\title{
EL DERECHO DE EMERGENCIA CONSTITUCIONAL EN ESPAÑA: HACIA UNA NUEVA TAXONOMÍA
}

PABLO FERNÁNDEZ DE CASADEVANTE MAYORDOMO 


\section{SUMARIO}

1. Introducción: la normalidad constitucional. 2. La anormalidad constitucional. 2.1. Las distintas posibilidades frente al hecho extraordinario. 2.1.1. La no constitucionalización de medidas extraordinarias para la protección del Estado. 2.1.2. La previsión constitucional de la concentración de poderes. 2.1.3. La constitucionalización detallada de uno o más supuestos excepcionales. 2.1.4. La labor paralela del legislador ordinario. 2.2. La doctrina española y su concepción del estado de excepción/derecho de excepción. 2.3. Una propuesta alternativa: el derecho de emergencia constitucional. 2.3.1. Perspectiva material: la afectación de los pilares del Estado de derecho como presupuesto para la apreciación de la emergencia constitucional. 2.3.2. Taxonomía: emergencia constitucional reglada versus emergencia constitucional no reglada y de cómo el derecho subsiste en ambos casos. 2.4. El derecho de emergencia constitucional en la práctica. 2.4.1. La emergencia constitucional reglada: más allá del artículo 116 CE. 2.4.2. La emergencia constitucional no reglada: el 23-F como ejemplo. 3. Conclusiones. BIBLIOGRAFÍA. 


\title{
EL DERECHO DE EMERGENCIA CONSTITUCIONAL EN ESPAÑA: HACIA UNA NUEVA TAXONOMÍA
}

\author{
PABLO FERNÁNDEZ DE CASADEVANTE MAYORDOMO ${ }^{1}$
}

\section{INTRODUCCIÓN: LA NORMALIDAD CONSTITUCIONAL}

Todo Estado de derecho, en cuanto que "Estado sujeto a normas"2, se articula con base en la aplicación habitual y general de una serie de reglas jurídicas preestablecidas cuyo fin último es la ordenación de la convivencia en sociedad. Qué derechos y libertades reconoce la Constitución, de qué forma pueden ser puestos en práctica, cómo se protegen, cuál es la manera en que los ciudadanos se valen de aquellos para legitimar el poder del Estado desde un punto de vista político, o de qué modo se ejerce el poder tanto a nivel horizontal como vertical. En eso puede decirse que consiste el derecho constitucional normal ${ }^{3}$. Partiendo de estas premisas, y como quiera que las normas de derecho constitucional se traducen en "mandatos concretos cuyo incumplimiento es susceptible de una sanción" ", las actuaciones contrarias al orden constitucional suelen ser afrontadas mediante el recurso a una serie de "instrumentos de defensa normalmente suficientes en sus fuerzas de orden público, en su legislación penal, en sus tribunales de justicia"5.

1 Profesor ayudante doctor (contratado doctor acreditado por la ANECA), Facultad de Ciencias Jurídicas y Sociales. Universidad Rey Juan Carlos. Edificio Departamental. Paseo de los Artilleros s/n. 28032. Madrid. Código orcid.org/0000-0003-1807-6583. Este artículo se encuentra vinculado al proyecto de investigación "Consecuencias jurídicas de la secesión de entidades territoriales de un Estado con especial referencia a las implicaciones en materia de derechos humanos. Enseñanzas para España" (DER2016-76312-P). La aproximación doctrinal alemana a este trabajo ha sido posible gracias a los recursos bibliográficos obtenidos durante mis estancias en el Instituto Max Planck de Derecho Público Extranjero y Derecho Internacional Público (Heidelberg, Alemania).

2 De Esteban, J. y González-Trevijano, P. (2004). Tratado de Derecho Constitucional. Tomo II, Madrid, Universidad Complutense de Madrid, $2^{\text {a }}$ edición, p. 469, para quienes la naturaleza del Estado de Derecho "se basa (...) en tres presupuestos delimitadores: normatividad, generalidad y normalidad".

3 Pérez Royo, J. (2016). Curso de Derecho Constitucional, Madrid, Marcial Pons, 15 a edición, pp. 843 a 855 .

${ }^{4}$ López Guerra, L. (1994). Introducción al Derecho Constitucional, Valencia, Tirant lo Blanch, p. 22.

5 Cruz Villalón, P. (1984). Estados excepcionales y suspensión de garantías, Madrid, Tecnos, p. 22. 
La cuestión es que, como bien señala uno de nuestros clásicos, constituye "un hecho evidente que los Estados no siempre viven en plena normalidad, con funcionamiento regular y perfecto de los organismos, instituciones y servicios en que su actuación se desenvuelve. Surgen a veces en la comunidad política perturbaciones de varia importancia que pueden (...) llegar incluso a conmociones que afectan en grado máximo a la existencia misma del Estado" 6 . En cualquiera de esas circunstancias, deberá estar justificado que las reglas habituales cedan en gran medida para lograr así una actuación más eficaz frente al peligro concreto y, con ello, una pronta restauración de la normalidad político-constitucional.

Aunque detalladas más adelante, nos referimos a amenazas para el orden constitucional como son, por ejemplo: el contexto de terrorismo global al que nos enfrentamos; las crisis migratorias que ponen en jaque la capacidad del Estado para controlar sus fronteras y garantizar la continuidad del sistema; las catástrofes naturales y crisis sanitarias de gran magnitud; o el fenómeno de los nacionalismos/populismos/extremismos, en cuanto que persiguen la destrucción del Estado de derecho como presupuesto del pluralismo político.

Señalado todo lo cual, este artículo tiene por objeto el análisis del tipo de régimen jurídico aplicable en momentos de anormalidad constitucional, labor de todo menos sencilla si tenemos en cuenta que ni siquiera hay respuesta consensuada para la pregunta sobre qué es más conveniente, si prever normativamente la solución a dispensar ante la anormalidad o no hacerlo. A partir de ahí, los desencuentros doctrinales son muy variados, constituyendo ejemplo de ello las discusiones acerca de: el momento desde el cual puede considerarse que el ordenamiento jurídico regula suficientemente el supuesto extraordinario concreto; qué naturaleza jurídica debe revestir la norma que contenga esa regulación, si así fuera; cómo debe procederse ante la anormalidad no regulada; en qué casos cabe hablar jurídicamente de "excepción” en la aplicación del derecho; o cuál es la fuerza suspensiva del ordenamiento jurídico que tienen las medidas de retorno a la normalidad constitucional. A la respuesta de estas y de otras cuestiones dedicamos nuestra atención, siendo importante dejar ya sentada la distinta óptica con la que este estudio aborda el fenómeno de la anormalidad constitucional, ello si lo comparamos con lo escrito hasta ahora por la generalidad de la doctrina patria.

${ }^{6}$ Pérez Serrano, N. (1984). Tratado de Derecho Político, Madrid, Civitas, 2a edición, p. 418. 


\section{LA ANORMALIDAD CONSTITUCIONAL}

\subsection{Las distintas posibilidades frente al hecho extraordinario}

Entendiendo por circunstancias extraordinarias aquellas "que pueden dar origen a la adopción de medidas excepcionales" ${ }^{7}$, dentro de los sistemas constitucionales es habitual que la academia enumere como modalidades básicas de respuesta frente a tal fenómeno las siguientes.

\subsubsection{La no constitucionalización de medidas extraordinarias para la protección del Estado}

Una primera posibilidad descrita consiste en el silencio del poder constituyente respecto de la implementación de medidas excepcionales de protección del Estado - hay textos constitucionales que incluso introducen prohibiciones expresas en ese sentido $^{8}$ - al considerar que el riesgo de prever tal opción es mayor que el de no establecer nada al respecto 9 . Es por eso que se trata de una fórmula únicamente factible en aquellos Estados en los que "existe la confianza de que no se aprovechará la situación de crisis para desnaturalizar el régimen constitucional" 10 .

En los sistemas que hayan optado por esta modalidad, la validación de la actuación estatal al margen de la normativa existente tendrá lugar normalmente a través del recurso a una técnica de origen inglés como es la exoneración parlamentaria — Bill of indemnity —. Ahora bien, para que esta se produzca, resultará imprescindible la apreciación de un estado de necesidad ${ }^{11}$, también denominado situación de fuerza mayor ${ }^{12}$.

\subsubsection{La previsión constitucional de la concentración de poderes}

O, dicho de forma más precisa, la constitucionalización de una "cláusula general"13, en virtud de la cual, "ante una emergencia genéricamente descrita, todos los poderes del Estado son susceptibles de quedar concentrados en una magistratura

${ }^{7}$ Fernández Segado, F. (1978). El estado de excepción en el derecho constitucional español, Madrid, Edersa, p. 18.

${ }^{8}$ Como ejemplo típico suele citarse el de la vigente Constitución belga de 1831, cuyo artículo 187 dispone que "la Constitución no podrá ser suspendida ni total ni parcialmente".

9 Cruz Villalón, P. (1984). Estados excepcionales y suspensión de garantías, op. cit., p. 28.

10 Pérez Royo, J. (2016). Curso de Derecho Constitucional, op. cit., p. 845.

11 Derecho de necesidad o Notrecht, en alemán, según terminología empleada por Loewenstein, K. (1986). Teoría de la Constitución, Barcelona, Ariel, $2^{a}$ edición (4a reimpresión), p. 286 —la obra original vio la luz en inglés y con otro título, en 1957-.

12 Wigny, P. (1952). Droit Constitucionnel, Bruxelles, Établissements Émile Bruylant, pp. 198-200.

13 Pérez Royo, J. (2016). Curso de Derecho Constitucional, op. cit., p. 845. 
única" ${ }^{14}$. Se trata de un instituto también conocido como dictadura constitucional o comisarial $^{15}$.

Amén del artículo 48 de la Constitución de Weimar de 1919, esta es la opción elegida, por ejemplo, por la Constitución francesa de 1958 - artículo 16-, siendo común denominador respecto de ambas la existencia de un control de esos poderes presidenciales $^{16}$.

\subsubsection{La constitucionalización detallada de uno o más supuestos excepcionales}

Esta técnica consiste en la previsión constitucional de una serie de situaciones extraordinarias en las que los poderes públicos podrán asumir determinadas competencias adicionales. Y aunque el artículo 116 de la Constitución española constituye clara muestra de ello, es la Ley Fundamental de Bonn de 1949 la que representa "el caso límite en abundancia de preceptos y situaciones contempladas"17.

En estos supuestos, la doctrina habla de una "correlación entre la emergencia contemplada y las modificaciones previstas en la vigencia de la Constitución; pero siempre sobre la base del carácter taxativo y limitado de estas modificaciones, lo que hace del ordenamiento constitucional un ordenamiento sustancialmente «resistente a la situación de excepción»"18.

Descritas brevemente las tres modalidades anteriores, no resulta sencillo determinar la mayor o menor conveniencia de unas sobre otras, pues de todas ellas cabe predicar una serie de ventajas y de inconvenientes. En efecto, es de esperar que el recurso al estado de necesidad/fuerza mayor favorezca la agilidad de la respuesta estatal frente a la amenaza concreta, ello si lo comparamos con los requisitos formales a observar en los sistemas jurídicos que hayan optado por constitucionalizar el fenómeno de la anormalidad constitucional —ya sea a través de la concentración de poderes o de la regulación más detallada-.

Pero claro, el aumento en ese dinamismo será directamente proporcional a la inseguridad jurídica generada ante el hecho extraordinario no regulado, problema

${ }^{14}$ Cruz Villalón, P. (1984). Estados excepcionales y suspensión de garantías, op. cit., p. 33.

15 No considerando acertado el empleo del término dictadura constitucional, Loewenstein, K. (1986). Teoría de la Constitución, op. cit., p. 284 y ss., prefiere hablar de "gobierno de crisis".

16 Del texto alemán se desprende, en palabras de Schmitt, C. (2013). Ensayos sobre la dictadura 1916-1932, Madrid, Tecnos, p. 288, el “apoderamiento para una comisión de acción no limitada jurídicamente, sobre cuyo presupuesto decide por sí mismo el presidente (desde luego, bajo el control del Reichstag (...)) y cuya ejecución de hecho tiene que realizarse mediante delegados comisariales”. En el caso francés, y desde la reforma constitucional de 2008, existe ya un efectivo control sobre el ejercicio de los poderes presidenciales a cargo del Consejo Constitucional — hasta entonces, el artículo 16 del Texto constitucional solo contemplaba el deber de consulta al propio Consejo Constitucional-.

17 Goig Martínez, J. M. (2009). "La defensa política de la Constitución. Constitución y estados excepcionales. (II) Un estudio de Derecho Constitucional comparado”. Revista de Derecho UNED, núm. 5, pp. 218 y ss.

${ }^{18}$ Cruz Villalón, P. (1984). Estados excepcionales y suspensión de garantías, op. cit., p. 32. 
frente al que la constitucionalización exhaustiva de la anormalidad constitucional parece ser el modelo que mejor parado sale ${ }^{19}$. Y lo bueno de este último es que, partiendo de que resulta imposible prever todos los peligros susceptibles de producirse a lo largo de la vida de un Estado, ante el hecho excepcional no regulado siempre cabrá la apreciación del estado de necesidad o de la fuerza mayor ya citados. Negar esta última posibilidad ${ }^{20}$ supondría aceptar la indefensión —y consiguiente derrotadel Estado de derecho cuando las previsiones normativas extraordinarias se revelaran insuficientes para asegurar la defensa efectiva del orden democrático establecido.

\subsubsection{La labor paralela del legislador ordinario}

Bien. Hasta aquí el breve estudio de la previsión —o no- de la anormalidad constitucional en el propio Texto constitucional. Pero conviene que los árboles no nos impidan ver el bosque. La realidad es que, desde hace ya varias décadas, existe una creciente tendencia a que el legislador ordinario asuma una labor más propia del poder constituyente —o del constituyente constituido, si hablamos de la reforma constitucional-, especialmente en materia de lucha antiterrorista.

Esto ha llevado a que, incluso en Estados que descartaron a priori la constitucionalización de situaciones extraordinarias, exista legislación en ese sentido, ya sea mediante la fórmula de las leyes de emergencia — de duración temporal—o a través de leyes antiterroristas específicas y de vigencia permanente, lo que implica, "en cierto modo, un cambio permanente en el sistema constitucional de derechos y procedimientos" 21 .

${ }^{19}$ Consciente de que existen situaciones excepcionales que pueden ser previstas en el ordenamiento jurídico y otras que no, Pérez Serrano, N. (1984). Tratado de Derecho Político, Madrid, Civitas, $2^{a}$ edición, pp. 415 y ss., ya defendió hace tiempo la necesidad de contemplar la propia excepción y de regularla jurídicamente. Así lo hizo también Loewenstein, K. (1986). Teoría de la Constitución, op. cit., p. 286. Entre nuestros contemporáneos, en esa misma dirección se manifiestan, entre otros, Fernández Segado, F. (1978). El estado de excepción en el derecho constitucional español, op. cit., p. 19; y Torres del Moral, A. (2004). Principios de Derecho Constitucional Español. Tomo I, Madrid, Universidad Complutense de Madrid, $5^{a}$ edición, p. 576, quien sostiene que "mucho más deferente con el principio de juridicidad estatal es (...) incorporar a la Constitución esos regímenes excepcionales”. En contra, Lafuente Balle, J. M. (1989). "Los estados de alarma, excepción y sitio (I)". Revista de Derecho Político, núm. 30, p. 30, para quien "la tesis que mejor responde frente a un supuesto de crisis constitucional es la (...) teoría de la fuerza mayor", dada "la desvirtualidad del Derecho de excepción".

${ }^{20}$ Como hace Serrano Alberca, J. M. (1985). “Artículo 116”, en Garrido Falla, F. (dir.), Comentarios a la Constitución, Madrid, Civitas, pp. 1771 y ss.

${ }^{21}$ Ferejohn, J. y Pasquino, P. (2004). “The law of the exception: a typology of emergency powers”. International Journal of Constitucional Law, vol. 2, Issue 2, p. 233. En relación con esta cuestión, resulta muy interesante la reflexión que realiza Agamben, G. (2004). Estado de excepción. Homo sacer II, 1, Valencia, Pre-Textos, p. 11, al afirmar que "frente a la imparable progresión de lo que ha sido definido como "una guerra civil mundial", el estado de excepción tiende a presentarse cada vez más como el paradigma de gobierno dominante en la política contemporánea. Esta conversión de una medida provisional y excepcional en técnica de gobierno supone la amenaza de transformar radicalmente — y de hecho la ha

(C) UNED. Revista de Derecho Politico

117

N. 107 , enero-abril 2020, págs 111-145 
Es el caso, por ejemplo, de la Ley antiterrorista de 2001 - USA Patriot Act-y su sustituta, la Ley de libertad estadounidense de 2015 —USA Freedom Act-, en Estados Unidos; de la Ley de Contraterrorismo y de Seguridad de 2015 - Counter-Terrorism and Security Act-, en Reino Unido ${ }^{22}$; o de la Ley relativa a las medidas complementarias de lucha contra el terrorismo, de 2016 - Loi du 27 avril 2016 relative à des mesures complémentaires en matière de lutte contre le terrorisme-, en Bélgica.

Más de lo mismo cabe señalar respecto de los ordenamientos constitucionales que sí prevén la anormalidad jurídico-política. En Francia, por ejemplo, donde además de la mencionada dictadura comisarial se ha constitucionalizado la declaración de guerra — artículo 35- y el estado de sitio - 36 — ${ }^{23}$, rige también la Ley n ${ }^{\circ} 55-385$, de 3 de abril de 1955, sobre el estado de emergencia - Loi $n^{\circ} 55-385$ du 3 avril 1955 relative à l'état d'urgence- De hecho, tras los atentados terroristas perpetrados en París, el 13 de noviembre de 2015, el país estuvo bajo la vigencia de dicho estado de emergencia durante casi dos años, hasta que fue reemplazado por medidas contempladas en una nueva Ley antiterrorista ${ }^{24}$ cuya aplicación no se encuentra sujeta a las condiciones temporales de aquel.

Y concluyendo con el caso español, observamos que el legislador también ha asumido una importante actividad en materia de emergencia constitucional. Desarrollo legislativo de los artículos 55 y 116 CE al margen —especial mención merece la Ley de Enjuiciamiento Criminal o LECrim, por la que las previsiones del artículo 55.2 CE han adquirido una vocación de permanencia ${ }^{25}$ —, la Ley Orgánica 6/2002, de 27 de junio, de Partidos Políticos —LOPP, en adelante_- y la consiguiente ilegalización de ciertos partidos políticos como instrumento en la lucha contra el terrorismo de ETA, constituye buena muestra de la tendencia apuntada.

transformado ya sensiblemente- la estructura y el sentido de las distinciones tradicionales de las formas de Constitución. El estado de excepción se presenta más bien en esta perspectiva como un umbral de indeterminación entre democracia y absolutismo".

${ }^{22}$ Y más recientemente, la Ley de Lucha contra el Terrorismo y Seguridad Fronteriza de 2019 -Counter-Terrorism and Border Security Act-.

${ }^{23}$ En opinión de Goig Martínez, J. M. (2009). "La defensa política de la Constitución. Constitución y estados excepcionales. (II) Un estudio de Derecho Constitucional comparado". Op. cit., p. 218, "La regulación francesa, con normas tan amplias, no constituye el mejor supuesto de medidas de emergencia institucionalizadas, puesto que tal concentración del poder en manos presidenciales, toda vez que suponen un exceso de confianza en las cualidades personales presidenciales y en sus intenciones, contienen los peligros inherentes a toda acumulación de poder".

${ }^{24}$ Loi du 30 octobre 2017 renforçant la sécurité intérieure et la lutte contre le terrorisme.

${ }^{25}$ Cruz Villalón, P. (2003-2004). "Veinticinco años de normalidad constitucional”. Revista de Derecho Político, núms. 58-59, p. 24. En Cruz Villalón, P. (1984). Estados excepcionales y suspensión de garantías, op. cit., p. 106, el propio autor alerta de que, a través del instrumento de la suspensión individual del artículo 55.2 CE “y las medidas procesales y penales complementarias el ordenamiento español se ha fabricado, en cierto modo, un estado excepcional «a la medida», superpuesto a la situación de normalidad". Esto le lleva a afirmar la existencia de un "fenómeno de «desplazamiento» del estado de excepción que, naturalmente, ya no cabe valorar tan positivamente". 


\subsection{La doctrina española y su concepción del estado de excepción/derecho de excepción}

Dentro del fenómeno de la anormalidad constitucional, es posición comúnmente aceptada en España la de condicionar la existencia del estado de excepción ${ }^{26} /$ derecho de excepción a la positivización de una serie de situaciones extraordinarias en la Carta Magna, de manera que, una vez surgidas estas, quede definido el régimen jurídico aplicable para lograr el retorno a la normalidad constitucional.

Así lo hacen, desde luego, tanto el Tribunal Constitucional ${ }^{27}$ como la doctrina especializada en las dos principales monografías que sobre la materia se han escrito en España ${ }^{28}$. En una de ellas, además, se concibe el estado excepcional como una modalidad dentro del derecho de excepción ${ }^{29}$, representando este, a su vez, la situación contrapuesta a la ausencia de toda previsión escrita frente a un determinado supuesto extraordinario ${ }^{30}$. Al margen de esta última cuestión, lo importante es dejar sentado el carácter abrumadoramente mayoritario que ha adquirido la opción favorable a condicionar la apreciación del estado de excepción/derecho de excepción a la existencia de regulación previa aplicable, una posición a la que se ha adscrito un amplio número de reconocidos constitucionalistas ${ }^{31}$.

26 Entendido el término en sentido amplio y no como medida normativa concreta prevista para una determinada situación extraordinaria — por ejemplo, el caso de nuestro estado de excepción del artículo 116 CE — Nada oponemos, por lo demás, al empleo del concepto a modo de adjetivo indicativo de la poca frecuencia con la que se manifiesta una situación extraordinaria.

27 STC 83/2016, de 28 de abril, FFJJ 7 y 10.

${ }_{28}$ Por un lado, Fernández Segado, F. (1978). El estado de excepción en el derecho constitucional español, op. cit., p. 18, al definir el estado de excepción "como el conjunto de circunstancias, previstas, al menos genéricamente, en las normas constitucionales, que perturban el normal funcionamiento de los poderes públicos del Estado y cuyo efecto inmediato es la concentración en manos del gobierno de poderes o funciones que, en tiempo normal, deben estar divididas o limitadas" — también en Fernández Segado, F. (1979). "La suspensión de garantías constitucionales en la nueva Constitución española". Revista de Estudios Políticos, núm. 7, pp. 310 y ss., al referirse a las situaciones del artículo 116 CE como "estados excepcionales”- - Y por otro, Cruz Villalón, P. (1984). Estados excepcionales y suspensión de garantías, op. cit., pp. 31 y ss., para quien "el presupuesto esencial del estado excepcional es la tipificación de la emergencia”.

29 Ibidem, p. 31, al llamar "estado excepcional al derecho de excepción basado en (...) la previsión de una serie de competencias extraordinarias taxativamente enumeradas". Junto al estado excepcional, el autor incluye como subtipos del derecho de excepción la figura de la "dictadura constitucional"; un "¿tertium genus?"; y el fenómeno de la "incorporación al "derecho ordinario" de institutos propios del derecho de excepción”.

30 Ibidem.

31 Como título de epígrafe en el que estudiar los estados de alarma, excepción y sitio, Serrano Alberca, J. M. (1985). “Artículo 116”, op. cit., p. 1770 alude al "régimen de los estados de excepción en la Constitución española de 1978”. Por su parte, Álvarez Conde, E. y Tur Ausina, R. (2016). Derecho Constitucional, Madrid, Tecnos, $6^{a}$ edición, p. 553, emplean el término "derecho de excepción” para referirse al caso excepcional", al "supuesto anormal" que "debe encontrarse también sometido a la correspondiente normatividad”. Para Blanco Valdés, R. L. (2018). “Artículo 55”, en Pérez Tremps, P., Saiz Arnaiz, A. y Montesinos Padilla, C. (dirs.), Comentario a la Constitución española. Libro bomenaje a Luis López Guerra. 40 aniversario 1978-2018, Valencia, Tirant lo Blanch, p. 969, "se califica como derecho

(C) UNED. Revista de Derecho Político

119

N. ${ }^{\circ}$ 107, enero-abril 2020, págs 111-145 
La doctrina mayoritaria de nuestro país ha decidido, en definitiva, dejar de lado los postulados de uno de los principales ideólogos — si no el más importante- en la materia. Nos referimos, cómo no, a Carl Schmitt, cuya deriva final hacia el autoritarismo no debe suponer un impedimento para reconocer la influencia de su obra académica en el derecho político-constitucional actual. Pues bien, a los efectos del presente artículo, resulta fundamental recurrir a su trabajo titulado "Teología política: cuatro capitulos sobre la doctrina de la soberanía" y publicado en $1922^{32}$, en el que dedica unas primeras páginas al acotamiento conceptual de lo que él entiende por "estado de excepción”.

En concreto, y con motivo de la discusión emprendida en torno al concepto de soberanía — de sobra conocida es su tesis de que "soberano es quien decide sobre el estado de excepción" 3 _ - el pensador alemán define el "caso excepcional" como "el que no se encuentra previsto en el ordenamiento jurídico vigente" ${ }^{34}$, dada la imposi-

de excepción al previsto en las Constituciones, y en las leyes que eventualmente vienen a darles desarrollo, con la finalidad de facilitar que los poderes públicos estén en condiciones de hacer frente a situaciones de emergencia política, económica o social”. En cuanto a García Morillo, J. (2013). Derecho Constitucional. Vol. I, Valencia, Tirant lo Blanch, $9^{a}$ edición, p. 423, señala que "en ocasiones se producen acontecimientos que perturban seriamente la convivencia pacífica y la normalidad constitucional. En tales casos resulta lógico que el propio ordenamiento prevea mecanismos de reacción para enfrentarse con la crisis creada con el fin de mantener el sistema establecido. Así surge lo que se ha denominado «derecho de excepción»". En la misma línea que los anteriores, por ejemplo, De Esteban, J. y González-Trevijano. (2004). Tratado de Derecho Constitucional. Tomo II, op. cit., pp. 479 y ss.; Goig Martínez, J. M. (2014). "Defensa política de la Constitución. Emergencia, excepcionalidad y democracia”. Cuestiones Jurídicas, vol. VIII, núm. 2, pp. 11-39; Lafuente Balle, J. M. (1989). "Los estados de alarma, excepción y sitio (I)”. Op. cit., pp. 25-54; López Guerra, L. (1994). Introducción al Derecho Constitucional, op. cit., pp. 209 y 210; Pascua Mateo, F. (2003). "Sinopsis artículo 116", en Constitución española, edición digital, consultada el 29 de junio de 2019, disponible en http://www.congreso.es/consti/constitucion/ indice/sinopsis/sinopsis.jsp?art=116\&tipo=2, p. 2; Pérez Royo, J. (2016). Curso de Derecho Constitucional, op. cit., pp. 843 a 855; Garrido López, C. (2017). "Naturaleza jurídica y control jurisdiccional de las decisiones constitucionales de excepción”. Revista Española de Derecho Constitucional, núm. 110, pp. 45 y ss.; Aba Catoira, A. (2011). "Estado de alarma en España”. Teoría y Realidad Constitucional, núm. 28, pp. 305-334, pp. 317 y ss.; o Requejo Rodríguez, P. (2018). “Artículo 55”, en Casas Baamonde, M. E. y Rodríguez-Piñero y Bravo Ferrer, M. (dirs.), Comentarios a la Constitución Española, Madrid, Boletín Oficial del Estado, p. 1522.

32 Nosotros consultamos una edición publicada en alemán en el año 2004.

33 En alemán, Ausnabmezustand, tal y como la define en Schmitt, C. (2004). Politische Theologie: vier Kapitel zur Lehre von der Souveranität, München, Duncker und Humblot, p. 13. Frente a esa teoría decisionista se posiciona el positivista Kelsen, H. (2009). Teoría Pura del Derecho, Buenos Aires, Eudeba, pp. 81 a 83 - la obra original data de 1934—, para quien únicamente la normalidad puede revestir interés científico, siendo la excepción a la norma una cuestión que queda para la sociología jurídica. Para un brillante análisis del diálogo soterrado mantenido entre ambos pensadores sobre sus respectivas concepciones del derecho público, consúltese De Miguel Bárcena, J. y Tajadura Tejada, J. (2018). Kelsen versus Schmitt. Política y derecho en la crisis del constitucionalismo, Madrid, Guillermo Escolar.

${ }^{34}$ Schmitt, C. (2004). Politische Theologie: vier Kapitel zur Lebre von der Souveranität, op. cit., pp. 13 y 14. 
bilidad de contemplar todos los supuestos de crisis para el Estado ${ }^{35}$. A continuación, y para mayor precisión, añade que el caso excepcional puede, a lo sumo: a) ser calificado como de extrema necesidad, de peligro para la existencia del Estado o de forma similar, pero resulta imposible su rigurosa delimitación. En estas situaciones, "los requisitos previos y el contenido de la competencia son necesariamente ilimitados" 36 . $\mathrm{Y}$ b), contener una especificación del sujeto autorizado a intervenir, siendo la inexistencia de control alguno sobre su actuación el elemento clave que, al momento, indicaría que aquel es el soberano - cosa que no cabe predicar, por cierto, del artículo 48 de la Constitución de Weimar ya citado ${ }^{37}$-.

Dejando a un lado la cuestión de la soberanía, lo que aquí realmente importa es la reflexión que el autor alemán realiza para aclarar que "no toda potestad extraordinaria, ni toda medida policial o decreto adoptados con carácter de urgencia constituyen, de por sí, un estado excepcional. Es necesario que esa potestad sea ilimitada en principio. Es decir, se requiere la suspensión total del ordenamiento jurídico vigente" 38 - justo lo contrario a lo que, como acabamos de ver, defiende la doctrina española-.

Para justificar esta situación de ausencia de un orden jurídico en la que se incurriría, el autor alemán realiza en su "Teoría de la Constitución", del año 1927, una interesante definición de la Constitución, tanto en sentido positivo como relativo ${ }^{39}$. Respecto a la primera, la define como el resultado de un acto llevado a cabo por el poder constituyente al decidir sobre la "forma y modo de la unidad política" 40 . En otras palabras, "en el fondo de toda normación reside una decisión política del titular del poder constituyente, es decir, del pueblo en la democracia, y del monarca en la monarquía" 41 . En cambio, Constitución en sentido relativo sería "la ley constitucional en particular" 42 que, a diferencia de la primera, sí puede ser suspendida durante el estado de excepción y violada por las medidas del estado de excepción ${ }^{43}$, precisamente para salvaguardar la forma política del Estado, la Constitución en sentido positivo.

${ }^{35}$ Como señala el autor en Ibidem, p. 14, "decidir si es posible o no eliminar el caso excepcional extremo no es un problema jurídico. Albergar la esperanza de que algún día se logrará su supresión es algo que depende de las propias convicciones filosóficas, históricas o metafísicas".

36 Ibidem.

37 Tal y como señala el mismo autor, en la medida en que el Presidente del Reich ostentaba la facultad para declarar el estado de excepción pero bajo el control del Parlamento o Reichstag.

38 Ibidem, p. 18. Amén, se entiende, de que las medidas puedan ser luego objeto de control parlamentario, elemento este último que, como señala el pensador alemán, es lo que impide afirmar que los plenos poderes que reconoce el artículo 48 de la Constitución de Weimar equivalgan a haber otorgado la soberanía.

39 También teoriza sobre los conceptos absoluto e ideal de Constitución.

40 Schmitt, C. (2011). Teoría de la Constitución, Madrid, Alianza Editorial, p. 58. Como decíamos, la versión original data de 1927.

${ }^{41}$ Ibidem, p. 60. Lógicamente, cuando habla de Monarquía lo hace refiriéndose a los regímenes absolutistas propios del Antiguo Régimen.

42 Ibidem, p. 45.

43 Ibidem, p. 64.

(C) UNED. Revista de Derecho Político

N.o 107, enero-abril 2020, págs 111-145 
Siendo razones de espacio las que nos han obligado a exponer la tesis de Schmitt de manera muy sintetizada, nos reiteramos en la opinión de que la misma debe ser muy tenida en cuenta a los efectos de cualquier estudio actual sobre la materia, sin que ello obste para que discrepemos, sobre todo, respecto de lo que constituyó una de las propuestas jurídico-políticas más dañinas para la moribunda democracia de Weimar: la atribución de plenos poderes al Presidente de la República para declarar el estado de excepción sin sometimiento a control alguno ${ }^{44}$. Pero dejando esta importante cuestión al margen —el desenlace es de sobra conocido-, creemos que su tesis sobre el estado de excepción sigue siendo muy útil en la actualidad, habiéndonos servido, de hecho, como inspiración de una parte de la construcción teórica que se propone en este trabajo.

\subsection{Una propuesta alternativa: el derecho de emergencia constitucional}

2.3.1. Perspectiva material: la afectación de los pilares del Estado de derecho como presupuesto para la apreciación de la emergencia constitucional

A modo de breve recapitulación, hasta ahora hemos tenido ocasión de comprobar que es posición doctrinal mayoritaria en España aquella que relaciona el estado de excepción/derecho de excepción con la previsión de unas reglas jurídicas específicas aplicables a circunstancias de anormalidad constitucional. También hemos visto que dicha concepción se contrapone a la de uno de los principales ideólogos en la materia como es Carl Schmitt, para quien el estado de excepción surge precisamente por la ausencia de normativa aplicable frente al caso extraordinario, con la consiguiente suspensión del ordenamiento jurídico vigente.

Dicho lo cual, y con el ánimo de rebatir ambos posicionamientos, procedemos sin más demora a la explicación de lo que nosotros entendemos por derecho de emergencia constitucional, entendido en un sentido material. Para ello, partiremos de la emergencia constitucional como concepto que debe ser empleado para aludir a ciertas situaciones que, por razón de su extrema gravedad, exigen la adopción de medidas extraordinarias de cara a una pronta restauración del orden público, del monopolio del derecho y, en definitiva, de la normalidad constitucional.

Para mayor precisión, serán de emergencia constitucional únicamente las amenazas que, comprometiendo gravemente el orden constitucional, hagan necesaria la afectación de cualquiera de los cuatro pilares básicos sobre los que se asienta nuestro

${ }^{44}$ Resolviendo de esta manera la duda de quién ha de ser soberano. Consúltese a estos efectos su obra "La defensa de la Constitución", publicada en 1931. 
Estado de derecho ${ }^{45}$. Esto es, el imperio de la ley elaborada por el Parlamento ${ }^{46}$, si la respuesta estatal a la emergencia no estuviera prevista en ella ${ }^{47}$; la eficacia de los derechos y libertades, mediante la adopción de medidas suspensivas en materia de derechos fundamentales ${ }^{48}$; el principio de división de poderes ${ }^{49}$, cuando se alteren las reglas habituales de distribución de los mismos; y la sujeción de la Administración al principio de legalidad ${ }^{50}$, si aquella se viera en la necesidad de implementar mecanismos de respuesta no previstos expresamente en la Constitución ni en el resto del ordenamiento jurídico.

Entran, por lo tanto, dentro de esta concepción, no solo las crisis institucionales que impiden el normal funcionamiento de los poderes públicos, sino fenómenos tan variados como, por ejemplo, ciertos desórdenes públicos, amenazas terroristas, catástrofes naturales, crisis sanitarias/humanitarias o accidentes, todos ellos —insistimosde tal magnitud que, comprometiendo gravemente el orden constitucional, exijan la alteración de, al menos, uno de los cuatro elementos indicados. Adjuntando, a continuación, un gráfico que sintetiza lo expuesto, simplemente señalar que la apreciación de todo supuesto de emergencia constitucional exigirá la aplicación del derecho de emergencia constitucional para su solución.

45 Aunque cada uno con sus matices, esos cuatro elementos básicos son enumerados por Álvarez Conde, E. (1990). El Régimen Político Español, Madrid, Tecnos, $4^{\text {a }}$ edición, pp. 34 a 37; Alzaga Villaamil, O., Gutiérrez Gutiérrez, I., y Rodríguez Zapata, J. (2007). Derecho Político Español según la Constitución de 1978 (I). Constitución y fuentes del Derecho, Madrid, Editorial Universitaria Ramón Areces, 4a edición, p. 275; y Sánchez Ferriz, R. (2009). El Estado Constitucional. Configuración bistórica y jurídica. Organización funcional, Valencia, Tirant lo Blanch, pp. 112 y 113.

46 Si bien ya "no tiene ese carácter absoluto y general propio del Estado liberal", tal y como se advierte en Álvarez Conde, E. (1990). El Régimen Político Español, op. cit., p. 36. Principalmente, porque la ley se encuentra sometida "a un sistema de controles, el más importante de los cuales es el control de la constitucionalidad de las leyes atribuido al Tribunal Constitucional...”.

47 O en la ley de leyes que es la Constitución española.

48 Sobre la naturaleza de la suspensión consúltense, entre otros, a Fernández Segado, F. (1978). El estado de excepción en el derecho constitucional español, op. cit., pp. 26 a 28, y a Requejo Rodríguez, P. (2001). “¿Suspensión o supresión de los derechos fundamentales?”. Revista de Derecho Político, núm. 51, p. 112.

49 Aunque, como se indica en Álvarez Conde, E. (1990). El Régimen Político Español, op. cit., p. 36, no puede "afirmarse que continúen estando en vigor los esquemas elaborados por Montesquieu (...). El principio de que cada función estatal debe ser ejercida por un solo órgano ha dejado paso, en nuestra Constitución, a la consagración de la colaboración de poderes y a la noción de la interdependencia”.

50 En los dos sentidos señalados por Sánchez Ferriz, R. (2009). El Estado Constitucional. Configuración histórica y jurídica. Organización funcional, op. cit., p. 113. En concreto, la legalidad de la Administración o su sujeción a la ley, "se entiende tanto en el sentido de que los órganos de la Administración no puedan derogar leyes previamente aprobadas por el Parlamento, como en el sentido de que la actividad administrativa halla en la ley, de una parte, un límite insuperable porque ha de respetarla forzosamente y, de otra, el propio fundamento de sus actuaciones y la determinación de sus fines".

(C) UNED. Revista de Derecho Político

N. ${ }^{\circ}$ 107, enero-abril 2020, págs 111-145 
Gráfico 1. Elementos materiales inherentes a toda emergencia constitucional

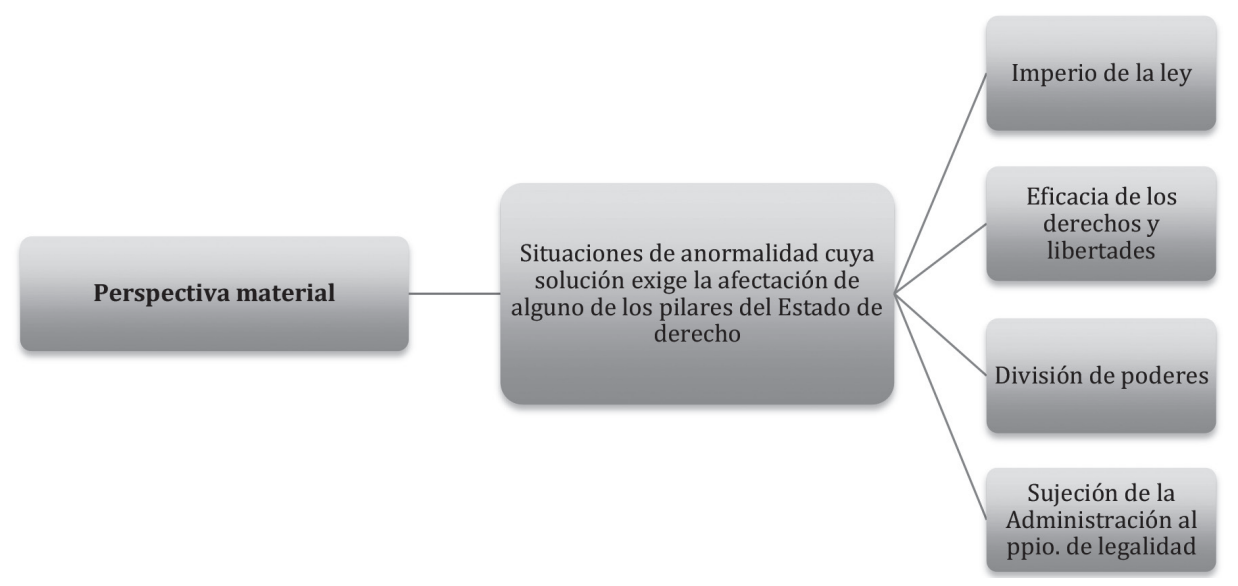

Fuente: elaboración propia.

\subsubsection{Taxonomía: emergencia constitucional reglada versus emergencia constitucional no reglada y de cómo el derecho subsiste en ambos casos}

Una vez constatada la situación de emergencia constitucional por la concurrencia de los requisitos que se acaban de señalar, aquella adquirirá una distinta denominación en función del tipo de cobertura jurídica con la que cuenten las medidas de defensa implementadas por el Estado. Como en el caso anterior, la explicación viene acompañada al final de una gráfica que pretende facilitar al lector el seguimiento de la teoría que aquí se propone.

\section{a. La emergencia constitucional reglada}

Si la respuesta estatal se encuentra previamente recogida en la Constitución o en las leyes, de tal forma que quepa deducir suficientemente: 1) cuáles son las situaciones de emergencia constitucional susceptibles de producirse; 2) a quién corresponde su apreciación, declaración o aplicación; 3) qué medidas cabe adoptar en cada caso; 4) y cuáles son los mecanismos de control y/o garantías existentes ante el uso de esta facultad $^{51}$, hablaremos de situaciones de emergencia constitucional reglada en las que se aplicará el derecho de emergencia constitucional reglada.

Ahora bien, para evitar una excesiva rigidez a la hora de valorar la concurrencia o no de las distintas condiciones apuntadas, es preciso alertar sobre la posibilidad de

51 Prácticamente los elementos que Cruz Villalón, P. (1984). Estados excepcionales y suspensión de garantías, op. cit., pp. 32 y 33, enumera como integrantes de lo que él entiende por derecho de excepción. 
que algunas de las mismas se encuentren descritas a través de conceptos jurídicos indeterminados, lo cual no debe conducir a la automática catalogación del concreto instituto de emergencia constitucional como "no reglado" 52 . Y, es que, esta última categoría está pensada para situaciones en las que ni la Constitución ni las leyes prevén mínimamente el marco jurídico dentro del que deberá desarrollarse la acción estatal frente a la amenaza concreta. Es decir, para nosotros, la no regulación se asocia principalmente con el estado de necesidad/fuerza mayor ya explicado, mientras que la dictadura comisarial o constitucional, tal y como está regulada en el artículo 16 de la Constitución francesa, bien puede catalogarse como emergencia constitucional reglada.

Por lo demás, solo añadir que no creemos que la aplicación de normativa constitucional a supuestos extraordinarios permita predicar una suspensión de la Carta Magna ${ }^{53}$ pues, en esas situaciones, lo que sucede es que las reglas jurídicas ordinarias,

52 Como bien señala González Hernández, E. (2019). “Interés general de España”. Eunomía. Revista en Cultura de la Legalidad, núm. 16, p. 185, "en principio, la indeterminación normativa no tiene por qué resultar distorsionadora de la labor habitual del operador jurídico y, más concretamente, del constitucionalista pues «Como principio no resulta ocioso insistir en el hecho inconcuso de que la Constitución Española, como las demás, utiliza palabras, expresiones o conceptos sin ocuparse de definirlos, por no ser misión suya y cuyo significado hay que extraer del sustrato cultural donde confluyen vectores semánticos ante todo y jurídicos en definitiva, con un contenido real procedente a su vez de distintos saberes y también de la experiencia», dice la STC 102/1995, de 26 de junio, F.j. $4^{0}$ ”.

53 En igual sentido, Pérez Serrano, N. (1984). Tratado de Derecho Político, Madrid, Civitas, $2^{a}$ edición, p. 479, cuando se refiere a la suspensión de derechos del artículo 55.1 CE. En concreto, sostiene que "la declaración de los estados de excepción no puede suponer la quiebra o suspensión completa de la Constitución" pues el recurso a aquella institución "representa en cierto modo su afirmación”. Del mismo modo, Álvarez Conde, E. (1990). El Régimen Político Español, op. cit., p. 249, defiende que lo que él entiende por derecho de excepción "no debe ser considerado como algo fuera de lugar del Estado de derecho. Es más, al ser el Estado de derecho un Estado absolutamente normativizado, donde se regulan relaciones de normalidad, hay que suponer que el caso excepcional, el supuesto anormal, debe encontrarse también sometido a la correspondiente normatividad”; o De Esteban, J. y González-Trevijano, P. (2004). Tratado de Derecho Constitucional. Tomo II, op. cit., p. 415. De opinión contraria es De Vergottini, G. (1983). Derecho Constitucional Comparado, Madrid, Espasa Calpe, pp. 190 y 191, quien considera "comprensible que en caso de peligro, cuando es imposible recurrir a las modalidades constitucionalmente previstas, se puede actuar en derogación de la Constitución, provocando su suspensión temporal, introduciendo una nueva normativa excepcional". En la misma línea, Goig Martínez, J. M. (2014). "Defensa política de la Constitución. Emergencia, excepcionalidad y democracia". Op. cit., p. 14. Por su parte, Cruz Villalón, P. (1984). Estados excepcionales y suspensión de garantías, op. cit., p. 19, sostiene que "el derecho de excepción" encuentra como "problema específico (...) que se trata de una garantía de la Constitución que funciona como suspensión temporal de la Constitución misma”. Ahora bien, en Cruz Villalón, P. (1981). "El nuevo derecho de excepción”. Revista Española de Derecho Constitucional, vol. 1, núm. 2, pp. 111 y 112, el propio autor apunta que las modificaciones operadas en el Estado de derecho durante la excepción, "con ser con ser puntualmente importantes, son exactamente eso, modificaciones puntuales, quedando el estado de derecho sustancialmente preservado a lo largo de la emergencia”.

(C) UNED. Revista de Derecho Político 
previstas para situaciones igualmente comunes, pasan a un segundo plano, ello en favor de otras de tipo extraordinario pero no menos constitucionales ${ }^{54}$.

\section{b. La emergencia constitucional no reglada}

Procediendo ver ahora qué sucede cuando la respuesta a la emergencia constitucional no se encuentra suficientemente prevista en la Constitución o en las leyes, lo primero que hay que señalar es que son esas anomalías las que dan lugar a la apreciación de lo que nosotros denominamos emergencia constitucional no reglada. Además, y aunque hemos preferido no incluir el término en el título del epígrafe para no introducir aún más ruido en el sistema, lo cierto es que será solo en estos supuestos donde, a nuestro modo de ver, tenga sentido hablar jurídicamente de una situación de excepción o, por emplear terminología típica entre nuestra academia, de un estado excepcional/de excepción —entendido, insistimos, en sentido amplio-.

Por lo tanto, y en relación con la posición que hemos visto mantiene la doctrina española especializada, no es que desechemos por completo el término estado excepcional/de excepción, sino que no creemos que sea adecuada su utilización para referirse, como hace aquella, a supuestos que sí se encuentran suficientemente regulados. A nuestro modo de ver, el estado excepcional/de excepción describe, en el contexto jurídico-político patrio, una situación absolutamente extrema e inverosímil — de ahí que, en su afán normativizador, ni el constituyente ni el legislador españoles hayan sido capaces de preverla - que se asemeja más a la fuerza mayor o al estado de necesidad antes descritos, institutos que ya hemos visto que justifican la actuación del poder directivo en situaciones no expresamente previstas en ninguna norma.

Ahora bien, dicha justificación debe estar condicionada siempre al respeto de ciertos criterios jurídicos, lo cual nos lleva a discrepar de quien afirme que, ante el supuesto extraordinario no regulado convenientemente, desaparece toda referencia jurídica que guíe la actuación defensiva del Estado. Es el caso de Schmitt que, para la apreciación del estado de excepción, ya hemos comprobado que exige "la suspensión total del orden jurídico vigente" 55 .

Para nosotros, en cambio, el derecho no desaparece completamente si, ante la ausencia de normativa concreta aplicable, la reacción estatal es coherente con ciertos principios y valores democráticos básicos. Es más, a nuestro modo de ver, y en contra

${ }^{54}$ En esa línea, Rossi, L. (1984). "Lo stato d'assedio nel diritto pubblico italiano". Archivio di diritto pubblico, Milán, Guiffrè, visto en Lafuente Balle, J. M. (1989). "Los estados de alarma, excepción y sitio (I)”. Op. cit., p. 27, autor este último que, unas líneas después de exponer la tesis del profesor italiano, se posiciona en contra de la misma.

55 Schmitt, C. (2004). Politische Theologie: vier Kapitel zur Lehre von der Souveranität, op. cit., pp. 18 y ss., añadiendo poco después que, "ante un caso excepcional, el Estado suspende el derecho en virtud del derecho a su propia conservación”. 
de lo afirmado por la doctrina española especializada ${ }^{56}$, es justamente en estas situaciones no reguladas —es decir, las que para nosotros dan lugar a la apreciación del estado excepcional o de excepción - donde el verdadero derecho constitucional de excepción puede hacer acto de presencia.

Para argumentar esta tesis, debemos partir de la opción del constituyente - en nuestro caso, el español de 1978 - por un sistema democrático, hito que ha de ser preservado por todos los medios de que necesite disponer el Estado. Es precisamente ese tipo de decisión la que, como ya hemos visto, sirve a Schmitt para fundamentar su concepto positivo de Constitución. La cuestión es que, mientras el autor alemán circunscribe los efectos de esa elección al ámbito político — la opción ciudadana por un sistema democrático sería una decisión política intangible que debe prevalecer a toda costa y la suspensión del ordenamiento jurídico sería necesaria para salvaguardar la voluntad popular-, para nosotros esa elección del constituyente tiene una clara vertiente jurídica si tenemos en cuenta que, en toda democracia constitucional, la Carta Magna supone la consagración de una serie de principios y valores jurídicos indeterminados ${ }^{57}$ que dan forma al propio modelo democrático.

Es decir, la opción del poder constituyente por el establecimiento de un Estado de derecho implica el compromiso ineludible con una serie de principios y valores jurídicos sin los cuales aquel dejaría de existir. Y, es que, como señala la principal doctrina, democracia "es método de gobierno, sí, pero también valores y principios compartidos por la generalidad de la ciudadanía (...) y que delinean una forma de vida política basada en el respeto y en la tolerancia, pero - y esto es muy indicativoque quiere seguir siendo democracia porque sabe (sabemos los ciudadanos) que no hay régimen político preferible a ella" 58 .

56 Con Fernández Segado, F. (1978). El estado de excepción en el derecho constitucional español, op. cit., p. 19 —aunque él emplea el término "estado de excepción”-; y Cruz Villalón, P. (1984). Estados excepcionales y suspensión de garantías, op. cit., pp. 31 y ss., a la cabeza, tal y como ya hemos visto.

57 Como se señala en Torres del Moral, A. (2004). Principios de Derecho Constitucional Español. Tomo I, op. cit., pp. 58 a 60; es habitual que el Tribunal Constitucional emplee indistintamente los términos "valores" y principios", "llamando, por ejemplo, de ambas maneras a la igualdad y a la seguridad jurídica; o hablando de los principios constitucionales de libertad, igualdad, justicia y unidad de España; o llamando valores a los principios democráticos de convivencia que menciona el artículo 27 de la Constitución (...); o incluso aludiendo conjuntamente a los valores, a los principios y a las opciones o decisiones constitucionales como informadores del Ordenamiento...”.

58 Torres del Moral, A. (2004). "Prólogo", en Tajadura Tejada, J. (autor), Partidos Políticos y Constitución: un estudio de la LO 6/2002, de 27 de junio, de Partidos Políticos y de la STC 48/2003, de 12 de marzo, Madrid, Civitas, p. 25. Por su parte, Català i Bas, A. H. (2012). "El modelo de democracia militante del Tribunal Europeo de Derechos Humanos", en Constitución y democracia: ayer y hoy. Libro homenaje a Antonio Torres del Moral, Vol. III, Madrid, Universitas, p. 3244, sostiene que "a nuestra democracia y a nuestra Constitución no les da igual la libertad que la esclavitud, la justicia que la injusticia o la igualdad que la desigualdad”. Para López Guerra, L. (1994). Introducción al Derecho Constitucional, op. cit., p. 31, la Constitución de 1978 constituye una norma que "responde a una concepción valorativa de la vida social, y viene a instaurar un marco básico de principios que han de conformar la convivencia”. En la misma línea, Lucas Verdú, P. (1984). Curso de Derecho Político. Vol. IV, Madrid,

(C) UNED. Revista de Derecho Politico

N. 107 , enero-abril 2020, págs 111-145 
Siguiendo esa lógica, cuando ni la propia Constitución ni sus leyes de desarrollo contengan unas pautas mínimas de actuación para enfrentar una emergencia constitucional concreta, lo que resulta indiscutible es que la respuesta estatal deberá tener como finalidad la defensa de esos valores y principios jurídicos inherentes al propio sistema democrático. Es esto lo que nos ha llevado a defender en otros trabajos el carácter militante o combativo de la democracia española ${ }^{59}$, por mucho que nuestra Constitución no contenga cláusula expresa de intangibilidad alguna ${ }^{60}$, como sí las tiene, por ejemplo, la Ley Fundamental de Bonn de 1949, paradigma de la democracia militante.

Dicho lo cual, y respecto a la inseguridad jurídica que se genera por la amplitud de esos principios y valores jurídicos ${ }^{61}$, esta no es, en ningún caso, mayor que si cre-

Tecnos, pp. 363 y ss.; Morodo, R. y Murillo de la Cueva, P. L. (2001). El ordenamiento constitucional de los partidos políticos, México, UNAM, pp. 137 a 139; y Tajadura Tejada, J. (2004). Partidos Políticos y Constitución: un estudio de la LO 6/2002, de 27 de junio, de Partidos Políticos y de la STC 48/2003, de 12 de marzo, Madrid, Civitas, pp. 100 y ss.

59 Por ejemplo, Fernández de Casadevante Mayordomo, P. (2018). "La prohibición de partidos políticos en Alemania. Del nuevo criterio de la potencialidad y la reciente reforma constitucional para la no financiación de formaciones antidemocráticas pero constitucionales". Revista de Derecho Político, núm. 102, p. 241; y (2019) ¿Son admisibles todos los proyectos en democracia? La izquierda nacionalista radical vasca: de su ilegalización a un discutible regreso a las instituciones públicas, Valencia, Tirant lo Blanch, p. 30. En Torres del Moral, A. (2004). "Prólogo", op. cit., p. 25, el autor sostiene que, "en España, los cuatro valores superiores del artículo 1.1 de la Constitución, más la dignidad humana, más media docena de otros valores que pueden extraerse de dicho texto o de su Preámbulo (...) nos persuaden de que la Constitución no es éticamente neutral ni políticamente es solo procedimental, sino algo más”.

${ }^{60}$ Es precisamente esa ausencia de límites materiales explícitos la que, a través de una confusa argumentación, ha llevado al Tribunal Constitucional a afirmar que "en nuestro ordenamiento constitucional no tiene cabida un modelo de democracia militante", en el sentido de que "se imponga, no ya el respeto, sino la adhesión positiva al ordenamiento y, en primer lugar, a la Constitución", pues "falta para ello el presupuesto inexcusable de la existencia de un núcleo normativo inaccesible a los procedimientos de reforma constitucional que, por su intangibilidad misma, pudiera erigirse en parámetro autónomo de corrección jurídica, de manera que la sola pretensión de afectarlo convirtiera en antijurídica la conducta que, sin embargo, se atuviera escrupulosamente a los procedimientos normativos". Y decimos que es confusa porque, a continuación, el Alto Tribunal declaró que "ciertamente, nuestra Constitución también proclama principios, debidamente acogidos en su articulado, que dan fundamento y razón de ser a sus normas concretas. Son los principios constitucionales, algunos de los cuales se mencionan en los arts. 6 y 9 de la Ley impugnada. Principios todos que vinculan y obligan, como la Constitución entera, a los ciudadanos y a los poderes públicos (art. 9.1 CE), incluso cuando se postule su reforma o revisión y hasta tanto ésta no se verifique con éxito a través de los procedimientos establecido en su Título X" —STC 48/2003, de 12 de marzo, FJ 7—. Es decir, el Tribunal Constitucional acaba reconociendo la existencia de límites materiales implícitos de cara a la modificación del Texto fundamental, abriendo la puerta a la existencia de modelos de democracia militante alternativos al alemán.

${ }^{61}$ Lo que ha llevado a la mayoría de la doctrina a afirmar el carácter exclusivamente procedimental - y por tanto, no valorativo- de la democracia, empezando por clásicos como Kelsen, H. (2009). Teoría Pura del Derecho, op. cit., p. 35, por ejemplo, cuando afirma que "una norma fundamental confiere a un hecho fundamental, como los mandamientos de Cristo o el establecimiento de la primera Constitución de un Estado la cualidad de hecho creador de normas. Solamente tiene un puro carácter formal, 
yéramos - como hemos visto que hacen otros - en la separación estanca entre derecho y medidas concretas frente a la emergencia constitucional no reglada. De hecho, para nosotros el problema se ve en cierto modo aliviado — que no subsanado, de ahí que hablemos de derecho sí, pero de excepción - si tenemos en cuenta que algunos de esos valores se encuentran explicitados en la Constitución española de 1978, lo que "les confiere un enorme refuerzo de eficacia jurídico-positiva" 62 , imponiendo "a los operadores jurídicos la obligación de procurarlos y desarrollarlos" ${ }^{63}$.

Ejemplo de esa juridificación son: 1) los valores superiores del ordenamiento jurídico que el artículo 1.1 CE propugna, palabra esta última que, como bien se afirma desde nuestra academia, "quiere decir defender, pero en latín el verbo propugno significa luchar, combatir para defenderse, para rechazar al enemigo (...). Por lo tanto, se reitera la lucha por el Estado de Derecho. Combatir por él y fortificarlo. (...) propugnar indica luchar, edificar, defenderse. El Estado que se constituye ha de luchar, ha de defenderse, ha de edificarse peleando y protegiéndose" ${ }^{64}$. De esta forma, toda reacción estatal frente a amenazas no regladas deberá tener como referencia la constitucionalización de unos valores superiores del ordenamiento jurídico que "poseen una naturaleza supraconstitucional que les hace aparecer como los cimientos del edificio constitucional"65. 2) Los principios generales del derecho —artículo 9.3 $\mathrm{CE}^{66}$ - , los cuales desempeñan una labor de concreción de los valores superiores del

dado que no representa en sí misma ningún valor moral o jurídico, pero permite la creación de tales valores por medio de normas positivas"; De Otto Pardo, I. (1985). Defensa de la Constitución y Partidos Políticos, Madrid, Centro de Estudios Constitucionales, pp. 38 y ss., y su enfoque "relativista, valorativamente neutral" del concepto de democracia; o Forsthoff, E. (1959). "Die Umbildung des Verfassungsgesetzes”, en Festschrift für Carl Schmitt, Berlin, Duncker y Humblot, pp. 117 y ss., cuando señala que atribuir al Texto fundamental la condición de "sistema de valor" facilitaría el aumento de la discrecionalidad judicial y, por ende, la inseguridad jurídica, al rechazar los principios clásicos de interpretación de la ley.

${ }^{62}$ Garrorena, A., visto en Torres del Moral, A. (2004). Principios de Derecho Constitucional Español. Tomo I, op. cit., p. 55.

63 Ibidem.

${ }^{64}$ Lucas Verdú, P. (1996). “Artículo 1: Estado social y democrático de derecho”, en Alzaga Villaamil, Ó. (dir.), Comentarios a la Constitución Española de 1978, Madrid, Edersa, pp. 102 y 103 . Además, de la STC 20/1987, de 19 de febrero, FJ 4, se desprende la estrecha vinculación de dichos valores superiores al derecho positivo, habiendo afirmado el Tribunal Constitucional que "la justicia no es un valor ajeno y contrario al ordenamiento positivo, sino uno de los valores superiores del mismo (art. 1.1 de la Constitución Española)". Más sobre la eficacia normativa de los valores, ver Torres del Moral, A. (2004). Principios de Derecho Constitucional Español. Tomo I, op. cit., pp. 58 a 60.

${ }^{65}$ De Esteban, J. (2001). Derecho Constitucional. Tomo I, Madrid, Universidad Complutense de Madrid, $2^{a}$ edición, p. 144.

${ }_{66}$ Tal y como los denomina el Tribunal Constitucional en su Sentencia 10/1989, de 24 de enero, FJ 3. Más al respecto, en Álvarez Conde, E. y Tur Ausina, R. (2016). Derecho Constitucional, op. cit., p. 58.

(C) UNED. Revista de Derecho Politico

N.o 107, enero-abril 2020, págs 111-145 
artículo $1.1 \mathrm{CE}^{67}$ y de información de todo el ordenamiento jurídico ${ }^{68}$, tal y como ha señalado el máximo intérprete de la Constitución. Pudiendo reducirse dichos principios a la seguridad jurídica y a la responsabilidad de los poderes públicos ${ }^{69}$, ya se ha dicho que el primero de ellos se ve inevitablemente afectado por la implementación de medidas de defensa no regladas, por eso es preferible tratar de normativizar al máximo las situaciones excepcionales. En cualquier caso, el carácter intangible de los valores superiores del ordenamiento jurídico ${ }^{70}$ provoca que, a diferencia de lo que sucedería si cupiera afirmar la suspensión total del ordenamiento jurídico ante la anormalidad constitucional no regulada, exista una frontera jurídica — más difusa de lo que sería deseable, es cierto- que nunca se podrá traspasar. Además, y en cuanto al principio de responsabilidad de los poderes públicos, veremos que pervive para aquellas situaciones en las que la respuesta estatal ante el peligro se revele desproporcionada.

Es hora, por lo tanto, de referirse a otro principio jurídico cuya observación resulta innegociable, tanto en relación con las situaciones extraordinarias reguladas como con las que no lo están, lo cual vuelve a demostrar que, incluso ante las amenazas más insospechadas, existe un suelo jurídico que no puede dejar de pisarse. En este sentido, y a la hora de evitar actuaciones desmesuradas por parte de los poderes públicos, es doctrina consolidada del Tribunal Constitucional la exigencia de respeto al principio de proporcionalidad, el cual hay que recordar que "«no constituye en nuestro ordenamiento un canon de constitucionalidad autónomo, cuya alegación pueda producirse de forma aislada respecto de otros preceptos constitucionales. Es un principio que cabe inferir de determinados preceptos constitucionales, siendo en el ámbito de los derechos fundamentales en el que normalmente resulta aplicable, y como tal opera como un criterio de interpretación que permite enjuiciar las posibles vulneraciones de concretas normas constitucionales (STC 215/2016, FJ 8)». El principio conlleva, con carácter general, el planteamiento de tres juicios sucesivos (de idoneidad, de necesidad y de proporcionalidad en sentido estricto) que la doctrina constitucional ha aplicado sobre todo para controlar medidas limitativas de los derechos fundamentales (por todas, STC 39/2016, de 3 de marzo, FJ 5)"71.

${ }^{67}$ En efecto, en su STC 27/1981, de 20 de julio, FJ 10, el Alto Tribunal señaló que los principios constitucionales del artículo 9.3 CE "no son compartimentos estancos, sino que, al contrario, cada uno de ellos cobra valor en función de los demás y en tanto sirva a promover los valores superiores del ordenamiento jurídico que propugna el Estado social y democrático de Derecho”, posición que ha sido reiterada por el Tribunal Constitucional, por ejemplo, en su Sentencia 140/2018, de 20 de diciembre, FJ 7. Y todo ello sin olvidar que, tal y como dispone el artículo 1 del Código Civil, los principios generales del derecho son fuente del derecho aplicable solo por detrás de la ley y de la costumbre, y tienen un carácter informador del ordenamiento jurídico.

68 STC 4/1981, de 2 de febrero, FJ 1.

69 Torres del Moral, A. (2004). Principios de Derecho Constitucional Español. Tomo I, op. cit., p. 60.

${ }^{70}$ De Esteban, J. (2001). Derecho Constitucional. Tomo I, op. cit., p. 144.

71 STC 89/2019, de 2 de julio, FJ 11. Más al respecto, en Arnold, R., Martínez Estay, J. I. y Zúñiga Urbina, F. (2012). "El principio de proporcionalidad en la jurisprudencia del Tribunal Constitucio- 
A partir de todo lo anterior, son distintas las conclusiones que cabe extraer: 1) Por un lado, que además de como propias del estado excepcional/de excepción, las medidas en defensa de principios y valores democráticos, siempre que sean respetuosas con el principio de proporcionalidad, son susceptibles de inclusión dentro de lo que nosotros entendemos por derecho constitucional de excepción, como ya hemos dicho. 2) Y por otro, que en el marco de nuestro Estado constitucional, la exención de responsabilidad ante la actuación no regulada: a) lejos de consistir en un acto político - como sucede con la exoneración parlamentaria a posteriori-, tendrá un marcado carácter jurídico, al depender de la observancia de los criterios jurídicos a los que venimos haciendo referencia y, en consecuencia; b) no deberá provenir del Parlamento —órgano que sí es soberano en el modelo anglosajón- sino, en todo caso, del Tribunal Constitucional — cuando así se le requiriese-, en cuanto que garante del Texto fundamental que, dado por el poder constituyente, permanece en vigor en lo que a sus principios y valores jurídicos esenciales se refiere. No en vano, el Alto Tribunal ha señalado que, "como regla general, los valores superiores del ordenamiento y los principios constitucionales pueden bastar para promover recursos o plantear cuestiones de inconstitucionalidad" 72 .

Un argumento jurídico adicional que impide afirmar la desaparición total del derecho en estos supuestos lo encontramos en la manera en que el Convenio Europeo de Derechos Humanos - CEDH - regula el caso extraordinario. Nos referimos a su artículo $15^{73} \mathrm{y}$, más concretamente, a la posibilidad de derogar ciertas obligaciones previstas en el Convenio en caso de guerra o de cualquier otro peligro público que amenace la vida de la nación.

Pues bien, de la redacción de dicho precepto se desprende —amén de la imposición de determinados límites formales y del carácter intangible de algunos derechos-, la existencia de ciertos principios jurídicos infranqueables para los Estados que, con el fin de superar situaciones extraordinarias de peligro, opten por derogar obligaciones previstas en el CEDH. Esos límites son, en primer lugar, el respeto -

nal". Estudios constitucionales, vol. 10, núm. 1, pp. 65-116.

${ }^{72}$ STC $117 / 1987$, de 19 de febrero, FJ 6.

73 Artículo 15 CEDH: "Derogación en caso de estado de excepción 1. En caso de guerra o de otro peligro público que amenace la vida de la nación, cualquier Alta Parte Contratante podrá tomar medidas que deroguen las obligaciones previstas en el presente Convenio en la estricta medida en que lo exija la situación, y a condición de que tales medidas no estén en contradicción con las restantes obligaciones que dimanan del derecho internacional. 2. La disposición precedente no autoriza ninguna derogación del artículo 2, salvo para el caso de muertes resultantes de actos lícitos de guerra, ni de los artículos 3 , 4 (párrafo 1) y 7. 3. Toda Alta Parte Contratante que ejerza este derecho de derogación tendrá plenamente informado al Secretario General del Consejo de Europa de las medidas tomadas y de los motivos que las han inspirado. Deberá igualmente informar al Secretario General del Consejo de Europa de la fecha en que esas medidas hayan dejado de estar en vigor y las disposiciones del Convenio vuelvan a tener plena aplicación".

(C) UNED. Revista de Derecho Politico

N.o 107, enero-abril 2020, págs 111-145 
también aquí- al principio de proporcionalidad en la medida implementada ${ }^{74}$. Y en segundo término, el cumplimiento de las obligaciones internacionales por parte de los Estados firmantes del CEDH, constituyendo un ejemplo de ello la prohibición de "discriminación alguna fundada únicamente en motivos de raza, color, sexo, idioma, religión u origen social” —artículo 4 del Pacto Internacional de Derechos Civiles y Políticos de 1966- ${ }^{75}$.

De esta manera, frente a la ausencia de todo orden jurídico en la excepción, predicado por Schmitt, la realidad es que, en el ámbito del Consejo de Europa —y en adición, por tanto, a lo ya señalado a nivel nacional - la respuesta estatal frente a la situación extraordinaria está también condicionada por la observancia de una serie de criterios jurídicos, correspondiendo al Tribunal Europeo de Derechos Humanos TEDH, en adelante $-{ }^{76}$, la fiscalización sobre la concurrencia de los mismos.

En otro orden de cosas, y respecto a qué ocurriría en caso de que la reacción estatal frente a la emergencia constitucional fuera aprovechada para perseguir objetivos antidemocráticos — por ejemplo, la instauración de un régimen autoritario—, la respuesta es simple si partimos de la concepción del derecho de emergencia constitucional como institución cuyo objetivo exclusivo es la preservación del orden democrático establecido.

En ese caso, el estado excepcional/de excepción no vendría acompañado de una aplicación del derecho constitucional de excepción, dado que la reacción estatal en supuesta defensa del orden constitucional sería contradictoria con las reglas jurídicas mencionadas. Al tratarse de una actuación contra constitutionem ${ }^{77}$, aquí sí se produciría, por lo tanto, una suspensión total del derecho ${ }^{78}$. Y en una situación como esta, de traición al régimen constitucional por parte del propio poder directivo establecido por aquel, corresponderá a toda institución que pudiera quedar al margen de esa

74 Lo que, según Lazkano Brotóns, I. y Lasagabaster Herrarte, I. (2009). “Artículo 15. Derogación en caso de urgencia”, en Lasagabaster Herrarte, I. (dir.), El Convenio Europeo de Derechos Humanos. Comentario sistemático, Madrid, Thomson Reuters-Civitas, p. 810, conlleva que "el Estado no puede derogar sino los derechos que la situación exija y en la estricta medida en que ello sea necesario".

75 En este sentido, por ejemplo, las SSTEDH de 10 de julio de 2001, Asunto Marshall c. Reino Unido; de 25 de mayo de 1993, Asunto Brannigan y McBride c. Reino Unido; o de 16 de septiembre de 2014, Asunto Hassan c. Reino Unido-

76 Más información en Goig Martínez, J. M. (2009). "La defensa política de la Constitución. Constitución y estados excepcionales (I)”. Revista de Derecho UNED, núm. 4, pp. 282 y ss.; y Remotti Carbonell, J. C. (1997). "El derecho de derogación en la jurisprudencia del Tribunal Europeo de Derechos Humanos: criterios generales”, en Gómez Sánchez, Y. (coord.), Los derechos en Europa, Madrid, UNED, pp. $245-270$.

77 En el caso español, expresamente prohibida, por ejemplo, cuando el artículo 9.1 CE dispone que "los ciudadanos y los poderes públicos están sujetos a la Constitución y al resto del ordenamiento jurídico".

78 Siendo muy conveniente, a este respecto, rescatar nuevamente las palabras del Tribunal Constitucional español cuando alertaba de la posibilidad de interponer recursos o cuestiones de inconstitucionalidad en relación con los valores superiores del ordenamiento y los principios constitucionales —STC $117 / 1987$, de 19 de febrero, FJ 6-. 
confabulación la articulación de las medidas que estuvieran a su alcance, las cuales, en el momento en el que respetasen los criterios jurídicos expuestos, serían —ya sísusceptibles de inclusión dentro de lo que nosotros entendemos por derecho constitucional de excepción ${ }^{79}$.

Y a una conclusión parecida habrá que llegar si el objetivo de la ruptura abrupta con el vigente orden constitucional fuera la instauración de otro sistema igualmente democrático. En esa hipótesis, la finalidad perseguida no puede ocultar la verdadera naturaleza de la acción llevada a cabo, que seguiría siendo contra constitutionem. Y, es que, hay que tener en cuenta que la Constitución española permite — bien es cierto que a través de un procedimiento extremadamente rígido - la reforma total ${ }^{80}$ de la misma, siempre — conviene insistir en ello- que la alternativa sea compatible con los principios y valores democráticos.

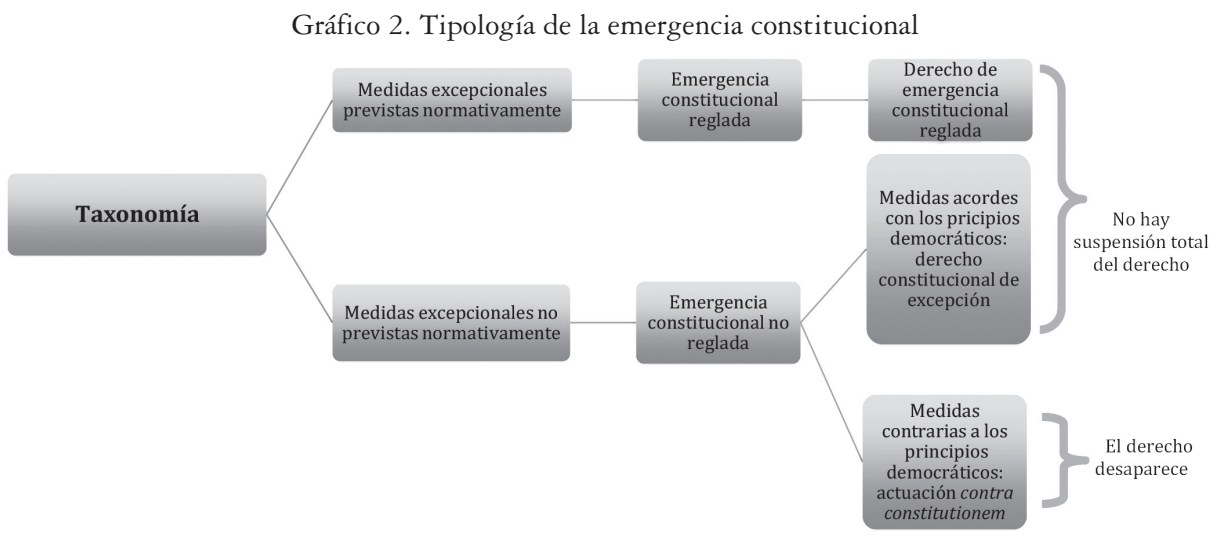

Fuente: elaboración propia.

\subsection{El derecho de emergencia constitucional en la práctica}

\subsubsection{La emergencia constitucional reglada: más allá del artículo 116 CE}

Como ha quedado expuesto con anterioridad, nuestra concepción del derecho de emergencia constitucional comprende una amplia panoplia de instrumentos a disposición del Estado de cara a enfrentar las situaciones de emergencia constitucional que

${ }^{79}$ Como veremos, la respuesta regia frente al golpe de Estado perpetrado el 23 de febrero de 1981 constituye un claro ejemplo de lo que se acaba de apuntar.

${ }^{80}$ Concepto cuya definición debe realizarse, según Vera Santos, J. M. (2016). "La reforma del procedimiento de reforma constitucional en España”. Revista de Derecho Político, N. ${ }^{\circ}$ 96, pp. 28 y 29, "atendiendo no sólo a criterios de cantidad, sino también y sobre todo, cualitativos". Ante la indefinición de los mismos, el autor propone que sea el Tribunal Constitucional el que deba contribuir a su concreción.

(C) UNED. Revista de Derecho Político

N. 107 , enero-abril 2020, págs 111-145 
puedan producirse a lo largo del tiempo. Esto provoca que el abanico de posibilidades de actuación reglada sea extenso y no fácilmente acotable, no existiendo un orden de prelación en el recurso a los diferentes mecanismos de defensa, excepción hecha del estado de sitio $^{81}$ que, como dispone el artículo 32.1 LOEAES, solo podrá ser declarado cuando la situación de peligro "no pueda resolverse por otros medios".

Pues bien, trayendo la teoría a la práctica constitucional, y al margen de los clásicos institutos del artículo $116 \mathrm{CE}^{82}$, representan supuestos de emergencia constitucional reglada, entre otros, la suspensión de derechos del artículo $55.2 \mathrm{CE}^{83}$, en relación con las investigaciones relativas a la actuación de bandas armadas o elementos terroristas, así como la archiconocida coerción estatal del artículo $155 \mathrm{CE}^{84}$. Nos explicamos brevemente.

En cuanto al instrumento previsto en el artículo 55.2 CE, constituye supuesto de emergencia constitucional desde el momento en el que su aplicación implica la suspensión en relación con los derechos: 1) a ser puesto en libertad o a disposición judicial de la autoridad judicial en un plazo máximo de setenta y dos horas —artículo 17.2 CE—; 2) a la inviolabilidad del domicilio — artículo 18.2 CE—; 3) al secreto de las comunicaciones —artículo 18.3 CE—. En todos los casos, el Tribunal Constitucional exige que la injerencia tenga lugar únicamente cuando las circunstancias así lo hagan imprescindible y tras llevar a cabo una adecuada ponderación de los intereses

81 "Última ratio del Estado de Derecho en su crisis", tal y como lo define Garrido López, C. (2007). "Sobre el estado de sitio, su régimen jurídico y el control jurisdiccional de su declaración". Revista de Derecho Político, núm. 68, p. 107.

82 Para un detenido estudio sobre la única — y discutida - ocasión en que se ha hecho uso de dicho precepto, consúltese Vidal Prado, C. y Delgado Ramos, D. (2011). “Algunas consideraciones sobre la declaración del estado de alarma y su prórroga”. Revista Española de Derecho Constitucional, núm. 92, pp. 243-265. En una monografía de próxima publicación tendremos ocasión además de discutir acerca del dudoso encaje que el estado de alarma tiene dentro de lo que para nosotros es el derecho de emergencia constitucional — La defensa de la Constitución, Aranzadi, Navarra, 2020—.

83 Artículo 55.2 CE: "Una ley orgánica podrá determinar la forma y los casos en los que, de forma individual y con la necesaria intervención judicial y el adecuado control parlamentario, los derechos reconocidos en los artículos 17, apartado 2, y 18, apartados 2 y 3, pueden ser suspendidos para personas determinadas, en relación con las investigaciones correspondientes a la actuación de bandas armadas o elementos terroristas".

84 Artículo 155 CE: “1. Si una Comunidad Autónoma no cumpliere las obligaciones que la Constitución u otras leyes le impongan, o actuare de forma que atente gravemente al interés general de España, el Gobierno, previo requerimiento al Presidente de la Comunidad Autónoma y, en el caso de no ser atendido, con la aprobación por mayoría absoluta del Senado, podrá adoptar las medidas necesarias para obligar a aquélla al cumplimiento forzoso de dichas obligaciones o para la protección del mencionado interés general. 2. Para la ejecución de las medidas previstas en el apartado anterior, el Gobierno podrá dar instrucciones a todas las autoridades de las Comunidades Autónomas".

Igualmente favorable a incluir los instrumentos consagrados en los artículos 55.2 y 155 CE dentro del "considerable elenco que excede los tres «estados excepcionales»", Cruz Villalón, P. (2017). "Entre proporcionalidad e identidad: las claves de la excepcionalidad en el momento actual”. Revista de Derecho Constitucional Europeo, núm. 27, p. 4. 
jurídicos en conflicto ${ }^{85}$. Ya se ha dicho, por lo demás, que el desarrollo del precepto es llevado a cabo, sobre todo, vía LECrim ${ }^{86}$.

Y respecto al artículo $155 \mathrm{CE}$, es igualmente susceptible de inclusión dentro de la emergencia constitucional, en la medida en la que, tal y como ha advertido el Tribunal Constitucional tras su reciente aplicación ${ }^{87}$, permite la "alteración temporal del funcionamiento del sistema institucional autonómico" 88 , incluida la "sustitución en el ejercicio de las funciones de esos órganos" $"$ — por ejemplo, el cese del Presidente de la Generalidad y de los demás miembros de su Gobierno, y la asunción de sus funciones por el Gobierno de la Nación- ${ }^{90}$.

Ambos mecanismos son además ejemplo de emergencia constitucional "reglada" dado que, a pesar de ciertas imprecisiones, sobre todo en el caso de la coerción estatal $^{91}$, su marco jurídico queda suficientemente definido en la norma correspondiente.

Al margen de lo anterior, y como decíamos al principio, la tendencia actual del legislador ordinario a regular en materia de emergencia constitucional constituye una realidad que no podemos ignorar. A partir de ahí, —y amén de la legislación dictada en desarrollo de los artículos 55 y $116 \mathrm{CE}$ - hemos creído conveniente dedicar al menos unas líneas a un instituto que, no estando expresamente previsto en la Constitución, ha contribuido de forma evidente a la protección del Estado de derecho

85 STC 199/1987, de 16 de diciembre, FFJJ 7, 8, 9 y 10.

${ }^{86}$ Estando con Requejo Rodríguez, P. (2004). "La suspensión individual de los derechos fundamentales en el artículo 55.2 CE”, en López Guerra, L. y Espín Templado, L. (coords.), La defensa del Estado, Valencia, Tirant lo Blanch, p. 276, cuando aboga por la conveniencia de evitar normas tan genéricas y amplias como la citada, en la medida en que "da a lo excepcional una apariencia de normalidad".

${ }^{87}$ Se acabó, por tanto, la responsabilidad y madurez política a la que hace referencia Cruz Villalón, P. (2003-2004). "Veinticinco años de normalidad constitucional". Op. cit., p. 192. Para una explicación sintética del instituto, González-Trevijano, P. (2006). La España constitucional, Valencia, Tirant lo Blanch, pp. 238 a 242.

${ }^{88}$ SSTC 89/2019, de 2 de julio, FJ 4; y 90/2019, de 2 de julio, FJ 4.

89 STC 89/2019, de 2 de julio, FJ 12.

90 En cambio, y como ha señalado el Tribunal Constitucional, la aplicación del artículo 155 CE no puede "dar lugar a la suspensión indefinida de la autonomía y, mucho menos, a la supresión institucional de la misma comunidad autónoma (...), ni consentiría limitar o excepcionar el «patrimonio común» de los ciudadanos constituido por los derechos fundamentales, los cuales establecen «una vinculación directa entre los individuos y el Estado y actúan como fundamento de la unidad política sin mediación alguna» (STC 25/1981, FJ 5)” —SSTC 89/2019, de 2 de julio, FJ 4; y 90/2019, de 2 de julio, FJ 4-.

${ }^{91}$ Y la utilización por el artículo 155 CE, según Vírgala Foruria, E. (2018). "El artículo 155 de la constitución: teoría y práctica”, en Pendás, B. (dir.), González Hernández, E. y Rubio Núñez, R. (coords.), España constitucional (1978-2018): trayectorias y perspectivas, Tomo V, Madrid, Centro de Estudios Políticos y Constitucionales, p. 4316, de "términos vagos e indeterminados con un fuerte componente de indefinición («no cumpliere las obligaciones», «interés general de España», «medidas necesarias») que son inevitables en todo precepto aplicable a situaciones excepcionales”. Recuérdese, por lo demás, que la regulación de este instituto se completa con lo dispuesto en el artículo 189 del Reglamento del Senado.

(C) UNED. Revista de Derecho Político

N. ${ }^{\circ} 107$, enero-abril 2020, págs 111-145 
frente a la amenaza terrorista. Nos referimos a la ilegalización de partidos políticos por la vía no penal, ello mediante la aplicación de la LOPP.

Efectivamente, la prohibición de partidos, entendida como método extraordinario de acción en defensa del orden constitucional, se erigió en instrumento fundamental de la lucha contra el terrorismo de ETA al permitir expulsar de la vida pública a una parte muy significativa de las formaciones políticas afines a la organización criminal. Recuérdese a estos efectos cómo, a modo de respaldo de lo dispuesto por el Tribunal Supremo y por el Tribunal Constitucional, el TEDH reconoció que el vínculo entre Herri Batasuna y ETA constituía una amenaza para la democracia ${ }^{92}$ y que la decisión de su ilegalización respondía a una "necesidad social imperiosa"93.

De cara a justificar la inclusión de la ilegalización de partidos dentro del concepto de emergencia constitucional que aquí se defiende ${ }^{94}$, hay que partir de la magnitud de la incidencia que una medida de ese calibre tiene sobre los derechos y garantías de las personas afectadas por la misma. En efecto, la aplicación de la LOPP perjudicó de pleno el ejercicio del derecho de sufragio pasivo del artículo $23.2 \mathrm{CE}^{95}$, sobre todo cuando el artículo 44.4 de la Ley Orgánica 5/1985, de 19 de junio, del Régimen Electoral General —LOREG_-, impide presentar candidaturas a las agrupaciones de electores que vengan a continuar o suceder la actividad de un partido político ilegalizado o suspendido ${ }^{96}$. Y además lo hizo con una duración en el tiempo muy superior

92 STEDH de 30 de junio de 2009, Asunto Herri Batasuna y Batasuna c. España, párrafos 89.

93 Ibidem, párrafo 91.

94 Es, además, emergencia constitucional reglada, puesto que la LOPP cumple con suficiencia cada uno de los requisitos antes enumerados de cara a su categorización como tal.

95 Incluso, como apunta Salazar Benítez, O. (2003). "La dudosa constitucionalidad de las limitaciones del derecho de sufragio pasivo previstas en la LO 6/2002, de Partidos Políticos (Comentario a las SSTS de 3 de mayo y a la STC 85/2003, de 8 de mayo)". Revista de Estudios Políticos (Nueva Época), Núm. 122, p. 112, "cabría plantearse la incidencia de dichas medidas en el derecho de sufragio activo, pues ambos «son aspectos indisociables de una misma institución, nervio y sustento de la democracia: el sufragio universal libre, igual, directo y secreto (arts. 68.1 y 69.1 CE)» (STC 24/90). De ahí que la vulneración del derecho de sufragio pasivo suponga siempre una vulneración también del derecho de sufragio activo". A tal respecto, el autor recuerda cómo, tras la anulación de casi todas las candidaturas presentadas por Autodeterminazioarako Bilgunea en 2003, nueve fueron los municipios navarros en los que no se pudieron celebrar las elecciones municipales por falta de candidaturas.

96 Tanto es así que una parte de la doctrina defiende la inconstitucionalidad de la medida. Es, por ejemplo, el caso de Pérez Royo, J. (2003). "Callejón sin salida”, en El País, edición digital, consultada el 15 de septiembre de 2019, disponible en https:/elpais.com/diario/2003/06/17/opinion/1055800808_850215.html; o de Salazar Benítez, O. (2003). "La dudosa constitucionalidad de las limitaciones del derecho de sufragio pasivo previstas en la LO 6/2002, de Partidos Políticos (Comentario a las SSTS de 3 de mayo y a la STC 85/2003, de 8 de mayo)". Op. cit., pp. 122 a 124 . Sea como fuere, lo cierto es que la constitucionalidad de dicha previsión fue salvada por el Tribunal Constitucional al afirmar que "partido político y agrupación electoral son términos tan heterogéneos que no cabe la continuidad, salvo, justamente, si la agrupación deja de ser propiamente tal, instrumentalizándose al servicio de la reactivación o continuidad de un partido disuelto. El artículo 44.4 LOREG pretende impedir esa clara defraudación de la legalidad, si bien para ello ha de perjudicarse, mediatamente, el ejercicio de un derecho individual que no ha sido objeto de la Sentencia de disolución” —Sentencia 85/2003, de 8 de mayo, FJ 26—. La adecuación a derecho del precepto fue posteriormente confirmada 
a la que pudiera esperarse si la emergencia constitucional fuese otra, lo cual refuerza el carácter excepcional de la institución. Y, es que, recordemos que la primera ilegalización tuvo lugar en el año 2003, siendo hasta 2011 numerosos los procesos electorales de los que la izquierda nacionalista radical vasca quedó excluida ${ }^{97}$.

Pero además del derecho de sufragio, el mecanismo de la ilegalización de partidos afectó sensiblemente a las garantías procesales de los encausados — artículo 24 CE-, tal y como reconoció el Tribunal Constitucional en repetidas ocasiones, al considerar "deseable un especial esfuerzo por parte del legislador en orden a lograr un mejor acomodo procesal” que permitiera aunar las garantías procesales del artículo $24 \mathrm{CE}$ con las "notas de celeridad, perentoriedad, preclusión de plazos y concentración de las fases de alegaciones y prueba" propias del proceso contencioso-electoral regulado en el artículo 49 LOREG $^{98}$.

Sea como fuere, la realidad es que el tratamiento jurídico dispensado a Herri Batasuna y a sus marcas sucesoras fue validado por el TEDH cada vez que este hubo de pronunciarse, lo cual lleva a considerar que la merma en los derechos y garantías de los afectados encontró justificación en la especial naturaleza del peligro al que debía enfrentarse el orden constitucional español.

\subsubsection{La emergencia constitucional no reglada: el 23-F como ejemplo}

Para nosotros, la respuesta extra constitutionem ofrecida por don Juan Carlos I tras el golpe de Estado perpetrado el 23 de febrero de 1981, constituye un claro ejemplo de aplicación del derecho constitucional de excepción ${ }^{99}$ ante situaciones de necesidad o de fuerza mayor, por antojarse el ordenamiento escrito insuficiente a la hora de prever una emergencia constitucional concreta.

en STEDH, de 11 de diciembre de 2007, Asunto Etxeberria y otros c. España, párrafo 50, al declarar el TEDH que "la disolución de los partidos políticos Batasuna y Herri Batasuna habría sido inútil si hubieran podido continuar su actividad de facto a través de las agrupaciones electorales litigantes".

${ }_{97}$ Para un detallado estudio de todos los procesos jurisdiccionales incoados contra la izquierda nacionalista radical vasca en aplicación de la LOPP, Fernández de Casadevante Mayordomo, P. (2019) ¿Son admisibles todos los proyectos en democracia? La izquierda nacionalista radical vasca: de su ilegalización a un discutible regreso a las instituciones públicas, op. cit., pp. 81 a 232.

98 STC 62/2011, de 5 de mayo, FJ 2. Y antes, en las SSTC 85/2003, de 8 de mayo, FJ 9; 68/2005, de 31 de marzo, FJ 4; 110/2007, de 10 de mayo, FJ 3; y 44/2009, de 12 de febrero, FJ 6.

99 En cambio, para De Otto Pardo, I. (1988). "El mando supremo de las Fuerzas Armadas". Revista Española de Derecho Constitucional, núm. 23, p. 14, "es claudicación inadmisible del constitucionalista limitarse a considerar las órdenes regias como anormalidad justificada por la anormalidad”. Es por ello que el autor defiende la incardinación de la actuación regia dentro de su facultad de "mando supremo de las fuerzas armadas". Muy interesante al respecto resulta la reflexión realizada por Aragón Reyes, M. (2004). "Veinticinco años de monarquía parlamentaria". Revista Española de Derecho Constitucional, núm. 70 , p. 23. Ver igualmente, Torres del Moral, A. (2003-2004). "Veinticinco años de Monarquía parlamentaria”. Revista de Derecho Político, núms. 58-59, p. 436.

(C) UNED. Revista de Derecho Político

N.o 107, enero-abril 2020, págs 111-145 
Y, es que, resulta lógico pensar que no estaba en el imaginario del poder constituyente español la posibilidad de que el Congreso de los Diputados y el Gobierno pudieran ser tomados como rehenes — tal y como sucedió-, lo cual justificó, de un lado, la extralimitación constitucional protagonizada por el Jefe del Estado al ordenar la retirada de las tropas sublevadas y; de otro, la creación de una especie de Gobierno provisional ajeno a la necesaria relación de confianza respecto de la Cámara Baja. Además, este ejemplo demuestra que la concentración de poder en una situación de emergencia constitucional no tiene por qué concretarse siempre en el Ejecutivo, aunque lo habitual será que así suceda.

Por lo demás, no queda más que insistir en que lo que esta taxonomía pretende es proporcionar una referencia jurídico-política a toda respuesta estatal frente a la emergencia constitucional, incluso en relación con las situaciones no regladas — que, por fortuna, en el ordenamiento jurídico español serán las menos- De hecho, si no introducimos más ejemplos prácticos dentro de esta categoría es por la labor constituyente y legislativa realizada en nuestro país, la cual reduce a la mínima expresión la posibilidad de que este tipo de situaciones pueda producirse. Ahora bien, por mucho que nuestro ordenamiento permita reconducir a la norma la inmensa mayoría de situaciones de anormalidad constitucional, a la vista está que, en ocasiones, la realidad llega a superar a la ficción ${ }^{100}$ y para esto también hay que estar preparado.

\section{CONCLUSIONES}

I. Todo Estado de derecho parte de la aplicación habitual y general de una serie de normas jurídicas preestablecidas, las cuales tienen como fin último la ordenación de la convivencia en sociedad. Existen, sin embargo, situaciones extraordinarias en las que, con el objetivo de una pronta restauración de la normalidad político-constitucional, las reglas habituales deben ceder en gran medida. Para reforzar la seguridad jurídica ante tales supuestos, resulta frecuente —además de deseable- la existencia de ciertas previsiones normativas dirigidas a regular la forma concreta de proceder ante la amenaza. Es lo que la doctrina española mayoritaria conviene en denominar estado de excepción/derecho de excepción, entendidos en sentido amplio.

100 Tomando como inspiración lo sucedido en Venezuela, pensemos en la hipótesis de que, como vía de escape ante la pérdida del control del Parlamento — en el caso español, por ejemplo, en forma de previsible derrota en la cuestión de confianza o de triunfo de la moción de censura-, el Jefe del Ejecutivo pusiera en marcha un procedimiento constituyente sujeto a unas nuevas reglas electorales favorables a sus intereses. La respuesta frente a esta amenaza contra el orden constitucional no podría venir lógicamente de la mano del artículo $116 \mathrm{CE}$ —ni de ningún otro mecanismo previsto en el ordenamiento jurídico español—, y ello por el papel decisivo que juega el Gobierno en la puesta en práctica de los institutos allí previstos. 
II. En este trabajo se aboga por una visión distinta del hecho jurídico-político excepcional, partiendo para ello de la emergencia constitucional como concepto que - entendido en sentido material — debe emplearse para aludir a ciertas amenazas que, por razón de su extraordinaria magnitud, no son superables a través de los medios habituales de acción del Estado. Para más precisión, serán de emergencia constitucional solo las situaciones que, comprometiendo gravemente el orden constitucional, exijan medidas jurídicas extraordinarias que afecten a cualquiera de los pilares del Estado de derecho como son: el imperio de la ley, la eficacia de los derechos y libertades mediante la adopción de medidas suspensivas en la materia, el principio de división de poderes y la sujeción de la Administración al principio de legalidad.

III. Reunidas esas condiciones y siempre que la forma de proceder ante el supuesto extraordinario se encuentre suficientemente detallada en la Constitución o en las leyes, hablaremos de situaciones de emergencia constitucional reglada en las que se aplicará el derecho de emergencia constitucional reglada.

IV. En cambio, si el hecho extraordinario no se encuentra tasado en ninguna norma escrita, no pudiéndose, por tanto, deducir suficientemente qué situaciones de emergencia constitucional pueden producirse; a quién le corresponde su apreciación, declaración o aplicación; qué medidas cabe adoptar; y qué mecanismos de control y/o garantías existen ante el ejercicio del poder excepcional, estaremos ante una emergencia constitucional no reglada y, por ende $-\mathrm{y}$ si de encajar nuestra teoría dentro de la terminología doctrinal habitual se trata-, ante un supuesto propio de lo que nosotros entendemos por estado excepcional/de excepción, entendido aquí también en sentido amplio. Por lo tanto, lejos de rechazar la validez de este último instituto, simplemente rehuimos la posición doctrinal mayoritaria adoptada en nuestro país, la cual asocia el estado excepcional/de excepción - y también el concepto de derecho de excepción - con supuestos de anormalidad constitucional cuya respuesta sí está regulada por el ordenamiento jurídico.

V. Por lo demás, y respecto a la posibilidad de hablar de un derecho constitucional de excepción ante la emergencia constitucional no reglada, la respuesta será afirmativa siempre y cuando la respuesta del poder directivo del Estado, en su misión de defensa de los valores democráticos consagrados en la Constitución, sea respetuosa con el principio de proporcionalidad en sus tres dimensiones — juicio de idoneidad, juicio de necesidad y juicio de proporcionalidad en sentido estricto-, tal y como lo describe el Tribunal Constitucional, por ejemplo, en su STC 89/2019, de 2 de julio, FJ 11. Rechazamos pues la posición doctrinal favorable a hablar de una suspensión total del derecho ante el caso extraordinario no previsto normativamente, siendo el artículo $15 \mathrm{CEDH}$ el que viene a confirmar que, incluso en situaciones de 
peligro para la pervivencia del Estado, existen ciertos criterios jurídicos que deben ser observados.

VI. Fundamentada la permanente concurrencia del elemento jurídico incluso en situaciones de anormalidad constitucional no regulada, identificamos al Tribunal Constitucional —y en el ámbito del Consejo de Europa, al TEDH - como el órgano jurisdiccional encargado del control jurídico sobre la respuesta estatal dispensada en defensa del orden constitucional. De esta manera, en el sistema constitucional español, el visto bueno ante la actuación estatal no regulada: 1) lejos de consistir en un acto meramente político como sucede con la exoneración parlamentaria a posteriori-, reviste un evidente carácter jurídico, al depender aquel de la observancia de los criterios jurídicos señalados. 2) No deberá proceder del Parlamento —institución que sí es soberana en el modelo anglosajón- sino, en todo caso, del Tribunal Constitucional — cuando así se le requiriese-, en cuanto que órgano garante de la Carta Magna que, dada por el poder constituyente, subsiste en situaciones de anormalidad constitucional, al menos en lo que a sus principios y valores jurídicos esenciales se refiere.

VII. Finalmente, son instrumentos propios del derecho de emergencia constitucional reglada, amén de lo previsto en el artículo 116 CE y de la suspensión de derechos contemplada en el artículo 55.2 CE: por ejemplo, la coerción estatal contemplada en el artículo 155 CE o la Ley Orgánica 6/2002, de 27 de junio, de Partidos Políticos. En cambio, la respuesta regia dispensada frente al golpe de Estado perpetrado el 23 de febrero de 1981, representa un claro ejemplo de lo que nosotros entendemos por derecho constitucional de excepción aplicable ante la emergencia constitucional no reglada.

\section{BIBLIOGRAFÍA}

Aba Catoira, A. (2011). "Estado de alarma en España”. Teoría y Realidad Constitucional, núm. 28, pp. 305-334.

Agamben, G. (2004). Estado de excepción. Homo sacer II, 1, Valencia, Pre-Textos.

Álvarez Conde, E. (1990). El Régimen Político Español, Madrid, Tecnos, $4^{a}$ edición.

Álvarez Conde, E. y Tur Ausina, R. (2016). Derecho Constitucional, Madrid, Tecnos, $6^{a}$ edición.

Alzaga Villaamil, O., Gutiérrez Gutiérrez, I., y Rodríguez Zapata, J. (2007). Derecho Político Español según la Constitución de 1978 (I). Constitución y fuentes del Derecho, Madrid, Editorial Universitaria Ramón Areces, vol. I, $4^{a}$ edición.

Aragón Reyes, M. (2004). "Veinticinco años de monarquía parlamentaria". Revista Española de Derecho Constitucional, núm. 70, pp. 11-25. 
Arnold, R., Martínez Estay, J. I. y Zúñiga Urbina, F. (2012). "El principio de proporcionalidad en la jurisprudencia del Tribunal Constitucional". Estudios constitucionales, vol. 10, núm. 1, pp. 65-116.

Blanco Valdés, R. L. (2018). “Artículo 55”, en Pérez Tremps, P., Saiz Arnaiz, A. y Montesinos Padilla, C. (dirs.), Comentario a la Constitución española. Libro homenaje a Luis López Guerra. 40 aniversario 1978-2018, Valencia, Tirant lo Blanch, pp. 969-980.

Català i Bas, A. H. (2012). "El modelo de democracia militante del Tribunal Europeo de Derechos Humanos”, en Constitución y democracia: ayer y hoy. Libro bomenaje a Antonio Torres del Moral, Vol. III, Madrid, Universitas, pp. 3243-3256.

Cruz Villalón, P. (1981). "El nuevo derecho de excepción”. Revista Española de Derecho Constitucional, vol. 1, núm. 2, pp. 93-128.

- (1984). Estados excepcionales y suspensión de garantías, Madrid, Tecnos.

- (2003-2004). "Veinticinco años de normalidad constitucional". Revista de Derecho Político, núms. 58-59, pp. 17-27.

- (2017). "Entre proporcionalidad e identidad: las claves de la excepcionalidad en el momento actual”. Revista de Derecho Constitucional Europeo, núm. 27, pp. 1-12.

De Esteban, J. (2001). Derecho Constitucional. Tomo I, Madrid, Universidad Complutense de Madrid, $2^{a}$ edición, p. 144.

De Esteban, J. y González-Trevijano, P. (2004). Tratado de Derecho Constitucional. Tomo II, Madrid, Universidad Complutense de Madrid, $2^{a}$ edición.

De Miguel Bárcena, J. y Tajadura Tejada, J. (2018). Kelsen versus Schmitt. Política $y$ derecho en la crisis del constitucionalismo, Madrid, Guillermo Escolar.

De Otto Pardo, I. (1985). Defensa de la Constitución y Partidos Políticos, Madrid, Centro de Estudios Constitucionales.

- (1988). "El mando supremo de las Fuerzas Armadas". Revista Española de Derecho Constitucional, núm. 23, pp. 11-43.

De Vergottini, G. (1983). Derecho Constitucional Comparado, Madrid, Espasa Calpe.

Ferejohn, J. y Pasquino, P. (2004). "The law of the exception: a typology of emergency powers". International Journal of Constitucional Law, vol. 2, Issue 2, pp. 210-239.

Fernández de Casadevante Mayordomo, P. (2018). "La prohibición de partidos políticos en Alemania. Del nuevo criterio de la potencialidad y la reciente reforma constitucional para la no financiación de formaciones antidemocráticas pero constitucionales". Revista de Derecho Político, núm. 102, pp. 235-273.

- (2019) ¿Son admisibles todos los proyectos en democracia? La izquierda nacionalista radical vasca: de su ilegalización a un discutible regreso a las instituciones públicas, Valencia, Tirant lo Blanch.

FERnÁNDEZ SEgAdo, F. (1978). El estado de excepción en el derecho constitucional español, Madrid, Edersa.

- (1979). "La suspensión de garantías constitucionales en la nueva Constitución española”. Revista de Estudios Políticos, núm. 7, pp. 299-312.

(C) UNED. Revista de Derecho Politico

N.o 107, enero-abril 2020, págs 111-145 
Forsthoff, E. (1959). "Die Umbildung des Verfassungsgesetzes”, en Festschrift für Carl Schmitt, Berlin, Duncker y Humblot.

García Morillo, J. (2013). Derecho Constitucional. Vol. I, Valencia, Tirant lo Blanch, 9a edición.

Garrido López, C. (2007). "Sobre el estado de sitio, su régimen jurídico y el control jurisdiccional de su declaración”. Revista de Derecho Político, núm. 68, pp. 107-142.

- (2017). "Naturaleza jurídica y control jurisdiccional de las decisiones constitucionales de excepción”. Revista Española de Derecho Constitucional, núm. 110, pp. 43-73.

Goig Martínez, J. M. (2009). "La defensa política de la Constitución. Constitución y estados excepcionales (I)". Revista de Derecho UNED, núm. 4, pp. 263-296.

- (2009). "La defensa política de la Constitución. Constitución y estados excepcionales. (II) Un estudio de Derecho Constitucional comparado”. Revista de Derecho UNED, núm. 5, pp. 211-251.

- (2014). "Defensa política de la Constitución. Emergencia, excepcionalidad y democracia”. Cuestiones Jurídicas, vol. VIII, núm. 2, pp. 11-39.

GonzÁlez Hernández, E. (2019). "Interés general de España”. Eunomía. Revista en Cultura de la Legalidad, núm. 16, pp. 183-197.

González-Trevijano, P. (2006). La España constitucional, Valencia, Tirant lo Blanch.

Kelsen, H. (2009). Teoría Pura del Derecho, Buenos Aires, Eudeba.

LAfuente Balle, J. M. (1989). "Los estados de alarma, excepción y sitio (I)”. Revista de Derecho Político, núm. 30, pp. 23-54.

LAZKano Brotóns, I. y Lasagabaster Herrarte, I. (2009). “Artículo 15. Derogación en caso de urgencia”, en Lasagabaster Herrarte, I. (dir.), El Convenio Europeo de Derechos Humanos. Comentario sistemático, Madrid, Thomson Reuters-Civitas, pp. 797-818.

Loewenstein, K. (1986). Teoría de la Constitución, Barcelona, Ariel, $2^{a}$ edición (4a reimpresión).

López Guerra, L. (1994). Introducción al Derecho Constitucional, Valencia, Tirant lo Blanch.

LuCAS Verdú, P. (1978). “Artículo 1: Estado social y democrático de derecho”, en Alzaga Villaamil, Ó. (dir.), Comentarios a la Constitución Española de 1978, Madrid, Edersa, pp. 79-164.

- (1984). Curso de Derecho Político. Vol. IV, Madrid, Tecnos.

Morodo, R. y Murillo de la Cueva, P. L. (2001). El ordenamiento constitucional de los partidos políticos, México, UNAM.

Pascua Mateo, F. (2003). "Sinopsis artículo 116", en Constitución española, edición digital disponible en http://www.congreso.es/consti/constitucion/indice/sinopsis/ sinopsis.jsp? art $=116 \&$ tipo= 2 , p. $1-4$. 
Pérez Royo, J. (2003). “Callejón sin salida”, en El País, edición digital, disponible en https://elpais.com/diario/2003/06/17/opinion/1055800808_850215.html.

- (2016). Curso de Derecho Constitucional, Madrid, Marcial Pons, $15^{\text {a }}$ edición.

Pérez Serrano, N. (1984). Tratado de Derecho Político, Madrid, Civitas, $2^{a}$ edición.

Remotti Carbonell, J. C. (1997). "El derecho de derogación en la jurisprudencia del Tribunal Europeo de Derechos Humanos: criterios generales", en Gómez Sánchez, Y. (coord.), Los derechos en Europa, Madrid, UNED, pp. 245-270.

Requejo Rodríguez, P. (2001). “'Suspensión o supresión de los derechos fundamentales?”. Revista de Derecho Político, núm. 51, pp. 105-137.

- (2004). "La suspensión individual de los derechos fundamentales en el artículo 55.2 CE”, en López Guerra, L. y Espín Templado, L. (coords.), La defensa del Estado, Valencia, Tirant lo Blanch, pp. 275-280.

- (2018). “Artículo 55”, en Casas Baamonde, M. E. y Rodríguez-Piñero y Bravo Ferrer, M. (dirs.), Comentarios a la Constitución Española, Madrid, Boletín Oficial del Estado, pp. 1520-1545.

Salazar Benítez, O. (2003). "La dudosa constitucionalidad de las limitaciones del derecho de sufragio pasivo previstas en la LO 6/2002, de Partidos Políticos (Comentario a las SSTS de 3 de mayo y a la STC 85/2003, de 8 de mayo)". Revista de Estudios Políticos (Nueva Época), Núm. 122, pp. 109-140.

SÁnChez Ferriz, R. (2009). El Estado Constitucional. Configuración bistórica y jurídica. Organización funcional, Valencia, Tirant lo Blanch.

Schmiтt, C. (2004). Politische Theologie: vier Kapitel zur Lebre von der Souveranität, München, Duncker und Humblot.

- (2011). Teoría de la Constitución, Madrid, Alianza Editorial.

- (2013). Ensayos sobre la dictadura 1916-1932, Madrid, Tecnos.

Serrano Alberca, J. M. (1985). “Artículo 116”, en Garrido Falla, F. (dir.), Comentarios a la Constitución, Madrid, Civitas, pp. 1764-1817.

Tajadura Tejada, J. (2004). Partidos Politicos y Constitución: un estudio de la LO 6/2002, de 27 de junio, de Partidos Políticos y de la STC 48/2003, de 12 de marzo, Madrid, Civitas.

Torres del Moral, A. (2003-2004). "Veinticinco años de Monarquía parlamentaria”. Revista de Derecho Político, núms. 58-59, pp. 427-445.

- (2004). Principios de Derecho Constitucional Español. Tomo I, Madrid, Universidad Complutense de Madrid, $5^{\text {a }}$ edición.

- (2004). "Prólogo", en Tajadura Tejada, J. (autor), Partidos Políticos y Constitución: un estudio de la LO 6/2002, de 27 de junio, de Partidos Políticos y de la STC 48/2003, de 12 de marzo, Madrid, Civitas, pp. 17-27.

Vera Santos, J. M. (2016). "La reforma del procedimiento de reforma constitucional en España”. Revista de Derecho Político, N. ${ }^{\circ}$ 96, pp. 13-48.

Vidal Prado, C. y Delgado Ramos, D. (2011). "Algunas consideraciones sobre la declaración del estado de alarma y su prórroga”. Revista Española de Derecho Constitucional, núm. 92, pp. 243-265.

(C) UNED. Revista de Derecho Politico

N. 107 , enero-abril 2020, págs 111-145 
Vírgala Foruria, E. (2018). "El artículo 155 de la constitución: teoría y práctica”, en Pendás, B. (dir.), González Hernández, E. y Rubio Núñez, R. (coords.), España constitucional (1978-2018): trayectorias y perspectivas, Tomo V, Madrid, Centro de Estudios Políticos y Constitucionales, pp. 4315-4336.

Wigny, P. (1952). Droit Constitucionnel, Bruxelles, Établissements Émile Bruylant.

Title:

Constitutional emergency law in Spain: towards a new taxonomy

\section{Summary:}

SUMMARY: 1. Introduction: constitutional normality. 2. Constitutional abnormality. 2.1. The various possibilities in the face of extraordinary situations. 2.1.1. The non-constitutionalization of extraordinary measures for State protection. 2.1.2. The constitutional regulation of the concentration of powers. 2.1.3. The detailed constitutionalization of one or more exceptional situations. 2.1.4. The parallel activity of the ordinary legislator. 2.2. The Spanish doctrine and its conception of the state of exception. 2.3. An alternative proposal: constitucional emergency law. 2.3.1. Material perspective: affecting the basic elements of the rule of law as a requirement for the outbreak of constitutional emergency. 2.3.2. Taxonomy: regulated constitutional emergency versus non-regulated constitutional emergency and how the law subsists in both cases. 2.4. Constitutional emergency law in practice. 2.4.1. Regulated constitutional emergency: beyond Article 116 SC. 2.4.2. Non-regulated constitutional emergency: 23-F as an example. 3. Conclusions. BIBLIOGRAPHY.

\section{Resumen:}

la normalidad constitucional consiste en la aplicación habitual y general de una serie de reglas jurídicas preestablecidas, ello con el objetivo de ordenar la pacífica convivencia ciudadana. Sin embargo, existen situaciones de peligro extraordinario en las que deberá estar justificado que las reglas habituales cedan en gran medida, ello con el objetivo de lograr una pronta restauración de la normalidad político-constitucional. Aunque anticipar todas las circunstancias excepcionales susceptibles de producirse es tarea del todo imposible, va en beneficio de la seguridad jurídica la previsión de, al menos, las amenazas más comunes. En esa regulación consiste lo que la doctrina española mayoritaria conviene en denominar estado de excepción o derecho de excepción, entendidos en sentido amplio. 
Este trabajo rehúye la anterior concepción terminológica, y lo hace en el marco de una nueva propuesta taxonómica aplicable al ámbito de la anormalidad constitucional. Así, partiendo de la diferenciación entre situaciones de emergencia constitucional reglada y no reglada, defendemos que la verdadera situación jurídica de excepción se manifiesta cuando, no existiendo regulación aplicable frente a la amenaza concreta, la reacción estatal no encuentra más límites que el respeto al principio de proporcionalidad en la defensa de los valores democráticos consagrados en la Constitución. Es esto, además, lo que impide afirmar la suspensión total del derecho frente al hecho excepcional no regulado, perteneciendo todas estas premisas jurídicas a lo que nosotros entendemos que es el derecho de emergencia constitucional.

\section{Summary:}

constitutional normality consists of the regular and general application of a series of pre-established legal rules, with the objective of achieving the peaceful coexistence of citizens. However, there are extraordinary danger situations in which some ordinary rules may not be enforced, in order to restore political-constitutional normality. Although it is impossible to anticipate all the anomalous circumstances likely to occur, it is in the interests of legal security that at least the most common threats should be foreseen. This is what the majority of Spanish doctrine agrees to call a state of exception or exception right, understood in a broad sense.

This work rejects the latter terminological conception, and this under a new taxonomic proposal applicable to the field of constitutional abnormality. On the basis of the differentiation between situations of regulated and non-regulated constitutional emergency, we defend the true legal exception is manifested when, in the absence of applicable regulation in case of a specific threat, the state reaction finds no other limits than the respect for the principle of proportionality in the defense of democratic legal values. It is the latter, in fact, which makes it impossible to confirm the total suspension of the Law in the face of a non-regulated exceptional circumstance, all these legal premises belonging to what we understand to be constitutional emergency law.

\section{Palabras clave:}

emergencia constitucional, crisis constitucional, estado de excepción, derecho de excepción, defensa del Estado, democracia militante.

\section{Keywords:}

constitutional emergency, constitutional crisis, state of exception, the law of the exception, State defence, militant democracy. 